\title{
Cyclodextrin-based Pickering emulsions: functional properties and drug delivery applications
}

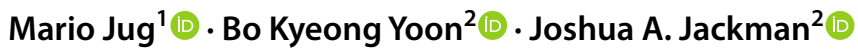

Received: 17 May 2021 / Accepted: 28 July 2021 / Published online: 3 August 2021

(c) The Author(s), under exclusive licence to Springer Nature B.V. 2021

\begin{abstract}
Cyclodextrins (CDs) are biocompatible, cyclic oligosaccharides that are widely used in various industrial applications and have intriguing interfacial science properties. While CD molecules typically have low surface activity, they are capable of stabilizing emulsions by inclusion complexation of oil-phase components at the oil/water interface, which results in Pickering emulsion formation. Such surfactant-free formulations have gained considerable attention in recent years, owing to their enhanced physical stability, improved tolerability, and superior environmental compatibility compared to conventional, surfactant-based emulsions. In this review, we critically describe the latest insights into the molecular mechanisms involved in CD stabilization of Pickering emulsions, including covering practical aspects such as methods to prepare CD-based Pickering emulsions, lipid encapsulation, and relevant stability issues. In addition, the rheological and textural features of CD-based Pickering emulsions are discussed and particular attention is focused on promising examples for drug delivery, cosmetic, and nutraceutical applications. The functionality of currently developed CD-based Pickering emulsions is also summarised, including examples such as antifungal uses, and we close by discussing emerging possibilities to utilize the molecular encapsulation of CD-based emulsions for translational medicine applications in the antiviral and antibacterial spaces.
\end{abstract}

Keywords Cyclodextrin $\cdot$ Pickering emulsion $\cdot$ Lipids $\cdot$ Stability $\cdot$ Drug delivery $\cdot$ Antifungals

\section{Introduction}

Emulsions are widely employed as dosage forms that provide parenteral nutrition and support administration of poorly soluble drugs, especially ones belonging to Class IV of the biopharmaceutical classification system. Furthermore, they are important formulations for the topical administration of such drugs to the skin and mucosal surfaces $[1,2]$. As a disperse system consisting of two immiscible liquids, emulsions are thermodynamically unstable and require stabilization by surfactants. The list of surfactants suitable for pharmaceutical application is restricted, especially in the case of emulsions aimed for parenteral or ocular administration. Even under such restrictions, surfactants may give

Mario Jug

mjug@pharma.hr

1 Faculty of Pharmacy and Biochemistry, University of Zagreb, A. Kovačića 1, Zagreb, Croatia

2 School of Chemical Engineering and Biomedical Institute for Convergence at SKKU (BICS), Sungkyunkwan University, Suwon 16419, Republic of Korea rise to various side effects, including acute hypersensitivity reactions, peripheral neurotoxicity, and membranedamaging effects leading to haemolysis and tissue irritation [3-5]. Furthermore, some of the surfactants can be potentially hazardous for the environment [6]. This has prompted research aimed at replacing conventional surfactants with other materials that can act as emulsifiers. In this regard, Pickering emulsions, i.e. emulsions stabilised by insoluble solid particles (Fig. 1), have emerged as a possible substitute for the ones formulated with traditionally used surfactants [7]. Their increasing popularity lays in the fact that Pickering emulsions show higher resistance to coalescence and Oswald ripening, resulting in higher stability compared to that of conventional, surfactant-based emulsions. In addition, a high internal phase volume fraction (>74\%) in Pickering emulsions can be prepared, which accounts for the enhanced cargo loading capacity [1, 7-9]. In the pharmaceutical field, Pickering emulsions are considered suitable for topical administration to the skin and mucosal surfaces of the body as well as for oral administration $[2,10]$ Different particles are used to stabilise Pickering emulsions, including those of inorganic origin like clay, hydroxyapatite, 


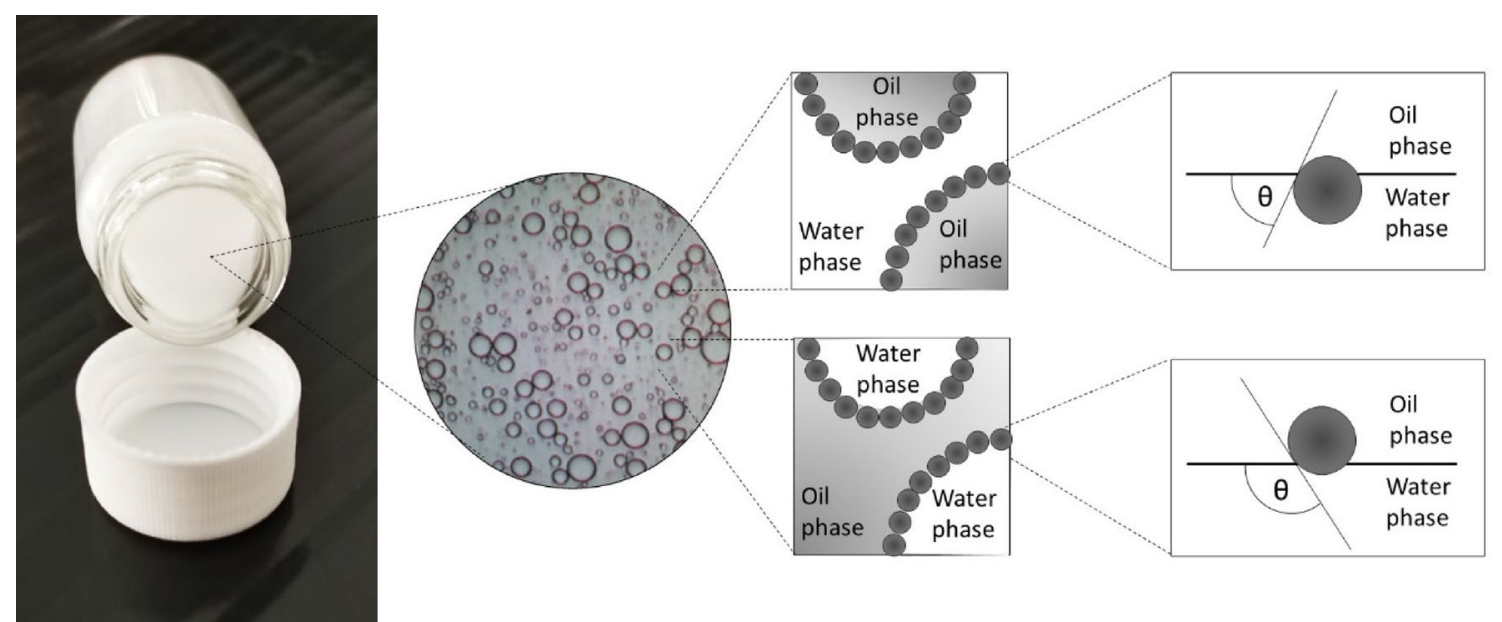

Fig. 1 Representative structure of a Pickering emulsion. Depending on the characteristics of the stabilising particles, $\mathrm{O} / \mathrm{W}$ or W/O type emulsions can be formed. Particles dominantly wetted with the water

magnesium hydroxide, magnetic iron oxides, and silica. However, such inorganic particles are mostly of submicron dimension and may accumulate in an organism upon administration since they are not biodegradable, which raises potential safety issues [11]. In this context, biodegradable polysaccharide-based particles like chitosan, cellulose, and starch are receiving attention as more suitable options along with other nature-derived materials such as pollen grains and processed derivatives thereof $[1,12,13]$.

Another attractive option for the development of biocompatible Pickering emulsions is the use of cyclodextrins (CDs) as emulsion stabilizers. CDs are a group of structurally related, cyclic oligosaccharides that consist of 6,7 , or 8 glucopyranose units $(\alpha \mathrm{CD}, \beta \mathrm{CD}$, and $\gamma \mathrm{CD}$, respectively), obtained by bacterial starch degradation. Chemical modification of naturally occurring CDs has resulted in numerous derivatives with enhanced functionality and improved safety profiles [14-16]. The structural features of CDs enable the spontaneous formation of supramolecular complexes in an aqueous environment by reversible inclusion of lipophilic drug molecules, or more often a sterically compatible lipophilic moiety, in the lipophilic central cavity of the CD molecule. The resulting inclusion complex acts as a carrier of the included drug in aqueous environments, thereby enhancing solubility, dissolution rate, and chemical stability, which contribute to drug bioavailability [17-19]. Furthermore, inclusion complexation can modify unfavourable organoleptic properties of drug molecules, converting liquids or even gases into technologically more acceptable solids and reducing tissue irritation at the drug administration site, which can improve patient compliance [20-22]. Besides serving as multifunctional pharmaceutical excipients, CDs are emerging as building blocks for advanced delivery systems and phase (three-phase angle, $\theta<90^{\circ}$ ) will form $\mathrm{O} / \mathrm{W}$ type emulsions, while particles dominantly wetted by the oil phase $\left(\theta>90^{\circ}\right)$ will form W/O type emulsions

enabling a new class of active pharmaceutical ingredients [23-25].

The aim of this article is to discuss the application of CDs in the development of Pickering emulsions that are suitable for biomedical applications. In contrast to previously mentioned solid particles, CDs stabilise Pickering emulsions by inclusion complexation with lipids and resulting selfassembly of the complexes formed at the oil/water $(\mathrm{O} / \mathrm{W})$ interface [26-28]. The mechanism by which CDs stabilize such systems will be discussed and illustrated by drawing on examples from the literature. Although some other reviews on this topic are available [7, 10,29], the aim of this paper is to provide an updated focus on emulsions containing oils that are approved for oral and topical administration, thus being suitable for development of pharmaceutical drug dosage forms, cosmetic formulations, and nutraceuticals. Functional properties of such CD-based Pickering emulsions will be discussed, including providing details on their preparation method, physical stability, rheological behaviour, drug release properties, and other functional characteristics that are of importance for applications such as drug delivery, cosmetics, and related fields.

\section{Interaction of cyclodextrins with lipids}

The hydrophobic central cavity of a CD molecule can encapsulate various lipophilic molecules by inclusion complex formation. Besides various low molecular-weight drugs that are the most common guests [30,31], inclusion complexation can also occur with different lipids, including free fatty acids, their mono-, di-, and triglycerides, and phospholipids [29, 32-34]. Such interactions are dependent on the structure 
of both the $\mathrm{CD}$ and lipid. In general, one $\mathrm{CD}$ molecule can embed 5 to $6 \mathrm{CH}_{2}$ moieties, as $\alpha \mathrm{CD}, \beta \mathrm{CD}$ and $\gamma \mathrm{CD}$ all have the same torus depth of $7.9 \AA$ [35]. However, some deviations have been observed that were caused by the different diameters of the CD central cavity. In the case of $\alpha C D$ and its derivatives, the narrower space of the central cavity (diameter 4.7-5.3 $\AA$, volume $174 \AA^{3}$ ) causes extension of the fatty acid chain, thus requiring a longer $\mathrm{CD}$ channel than the actual chain length of the fatty acids. The opposite case has been observed for $\beta C D$ and its derivatives that have a larger central cavity (diameter 6.0-6.5 $\AA$, volume $262 \AA^{3}$ ) in which fatty acids are slightly twisted, leading to better intramolecular interactions than with $\alpha \mathrm{CD}[29,33]$. The larger dimensions of the $\gamma \mathrm{CD}$ central cavity (diameter 7.5-8.3 $\AA$, volume $427 \AA^{3}$ ) permit further coiling of the fatty acid hydrocarbon chain. By that, the whole hydrocarbon chain up to $18 \mathrm{C}$ in length, as well as the carboxyl end of the fatty acid, may be included inside the $\gamma \mathrm{CD}$ central cavity [36]. Consequently, a molar ratio of 3, 2, and 1.5 was observed for linoleic acid (C18:2) inclusion complexes with $\alpha \mathrm{CD}, \beta C D$, and $\gamma \mathrm{CD}$, respectively [32]. Due to steric reasons, $\alpha \mathrm{CD}$ and derivatives have higher efficiency for interactions with short $\left(\leq \mathrm{C}_{8}\right)$ and long-chain $\left(\geq \mathrm{C}_{12}\right)$ fatty acids and their glycerides. On the other hand, $\beta C D$ and derivatives are more suitable for the inclusion complexation of (poly)unsaturated fatty acids and their glycerides as well as for intermediate chain-length fatty acids $\left(\approx \mathrm{C}_{10}\right)$ [29]. Besides fatty acids, CDs can interact with their glycerides, but the complexation affinity decreases in the following order: fatty acids $>$ mono- $>$ di- $>$ triglycerides $[29,32] . \alpha C D$ and $\beta C D$ soluble complexes will be formed only with free fatty acids and monoglycerides, while triglycerides and phospholipids will form insoluble complexes. Chemically modified CDs, especially methylated derivatives, are very potent solubilizers of fatty acids. For example, randomly methylated $\alpha \mathrm{CD}$ (RAMEA) and $\beta C D$ (RAMEB) increased the aqueous solubility of $\mathrm{C} 12-\mathrm{C} 18$ fatty acids by $250-1660$ and $240-910$ times, respectively [32]. Furthermore, dimethyl $\beta C D$ (DIMEB) shows an outstanding solubilising effect for phospholipids and can extract them from bilayers and even disrupt unilamellar liposomes at bulk concentrations above $50 \mathrm{mM}[34,37]$. Beside solubilization and extraction of phospholipid molecules from lipid bilayers, CD complexation may significantly enhance the chemical stability of included fatty acids, which is of particular importance for polyunsaturated $\omega$-fatty acids $[38,39]$. $\beta C D$ complexation enhances both thermal and oxidative stability of polyunsaturated $\omega$-fatty acids in complex matrices like natural oil and oleogels [39-41]. Furthermore, complexation enhances their technological properties by converting them into compactible powders [41, 42]. Finally, the formation of $\mathrm{CD} /$ lipid inclusion complexes is of substantial importance for CD-based stabilization of Pickering emulsions [26-28] and will be discussed in following section.
The high affinity of $\beta C D$ and its methylated derivatives for cholesterol complexation is well described in the literature and accounts for toxicological effects caused by parenteral administration [32, 43-46]. The insoluble $\beta C D /$ cholesterol complexes aggregate in the kidney as intracellular needle-like crystals that cause kidney damage, while cholesterol depletion from erythrocyte membranes caused by methylated $\beta C D$ s can result in haemolysis [16, 47]. According to currently available data, inclusion complexation of cholesterol with CDs has no relevance to the stabilization mechanism of Pickering emulsions, although such insoluble complexes may find application in topical formulations. Nevertheless, cholesterol complexation by CDs is currently under investigation as a new therapeutic approach to treat some inherited metabolic diseases like Nieman-Pick type C disease [48, 49] and atherosclerosis [50], and to enhance artificial insemination [51].

\section{Mechanism of Pickering emulsion stabilization by CDs}

CDs alone, with the exception of methylated $\beta C D$ derivatives, do not decrease the air/water surface tension of water [28]. The mechanism of Pickering emulsion stabilization by CD includes several steps (Fig. 2). The first step occursimmediately after mixing the oil and aqueous $\mathrm{CD}$ solution and involves inclusion complexation of lipophilic components of the oil phase by CDs. The formed complexes usually involve only partial inclusion of the lipophilic component in one cyclodextrin molecule, resulting in a structure resembling that of a surface-active molecule: $\mathrm{CD}$, within the complex formed, corresponds to the hydrophilic head while the lipophilic chain protruding from the $\mathrm{CD}$ cavity behaves as the lipophilic tail. Such structures are aligned at the oil/water $(\mathrm{O} / \mathrm{W})$ interface like conventional surfactants where the $\mathrm{CD}$ part of the complex formed is immersed in the water phase of the emulsion, while the lipophilic tail is oriented toward the oil phase. This happens at low CD concentration and is believed to be the main mechanism of the emulsifying activity of highly soluble cyclodextrin derivatives [28]. At higher $\mathrm{CD}$ concentrations, especially in the presence of naturally occurring CDs, inclusion complexation continues resulting in poly(pseudo)rotaxane formation. Such structures, formed by the threading of more than one $\mathrm{CD}$ molecule along the length of the lipophilic chain molecule, are suggested to occur in several emulsion-containing organic solvents like tetradecane (TD). In this case, the molar stoichiometry of the complexes formed are approximately 6.8:1 and 5.7:1 for $\alpha \mathrm{CD} / \mathrm{TD}$ and $\beta \mathrm{CD} / \mathrm{TD}$, respectively, and remain as such even if the oil fraction increases [27, 28]. Similar structures may be presumed for inclusion complexes of liquid paraffin and isopropyl myristate [26]. As such, the complexes 


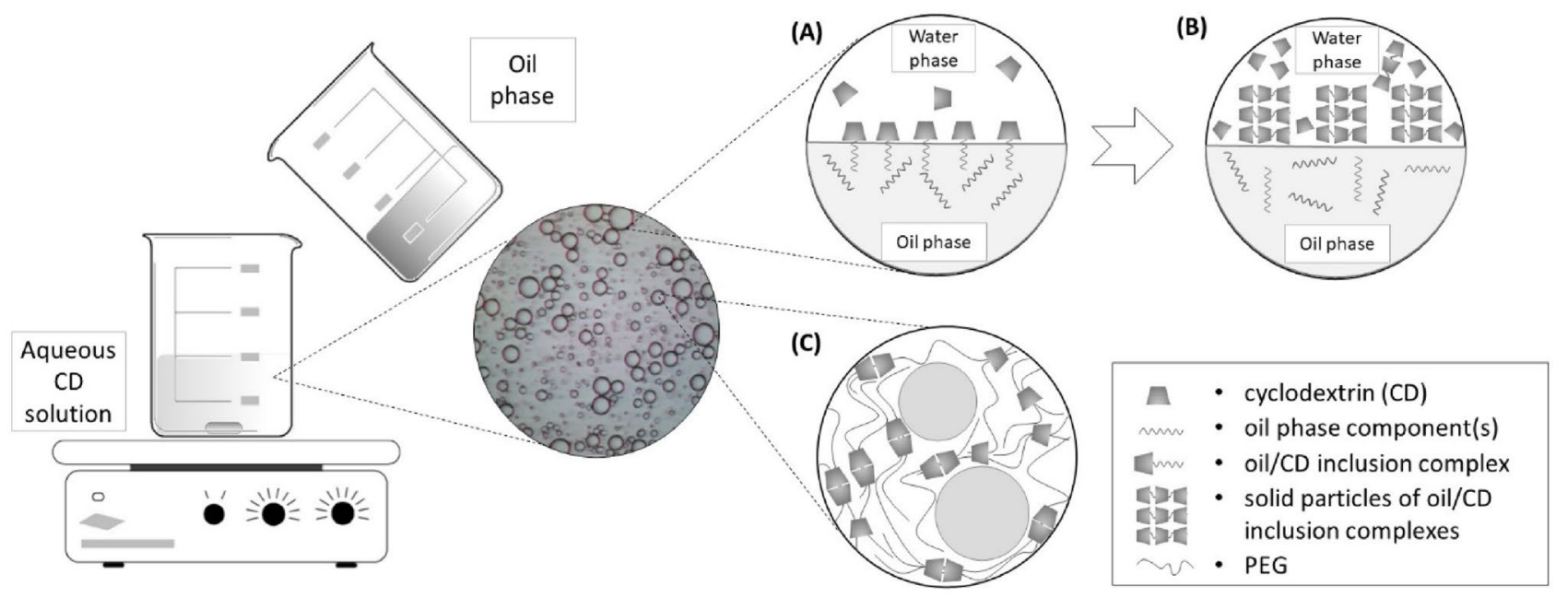

Fig. 2 Mechanism of Pickering emulsion stabilisation with CDs: A formation of inclusion complexes at the $\mathrm{O} / \mathrm{W}$ interface at low $\mathrm{CD}$ concentration and/or early stages of formation; $\mathbf{B}$ crystallisation of

are generally poorly soluble and can precipitate at the $\mathrm{O} / \mathrm{W}$ interface, resulting in Pickering emulsion formation. Typically, such crystalline structures formed at the O/W interface can be observed by optical microscopy and cause a significant decrease in $\mathrm{O} / \mathrm{W}$ interphase tension [26, 52-55]. Leclercq [56] proposed the term "colloidal tectonics" to describe this assembling process occurring at the $\mathrm{O} / \mathrm{W}$ interface, which is based on molecular recognition operating at the level of the complementary building blocks or tectons (CDs as hydrophilic and lipids as hydrophobic tectons), and provides an infinite variety of reversible (supra)colloidal systems with predictable, versatile and switchable properties. At higher CD concentrations, such solid particles are present in the aqueous phase of emulsions too, forming a three-dimensional network that contributes to the rheological properties and physical stability of the emulsion [27, 57]. The morphological properties of the formed solid inclusion complexes depend on the type of CDs employed. For example, $\alpha \mathrm{CD} /$ tetradecane microrods formed at the $\mathrm{O} / \mathrm{W}$ interface appear as microrods that are longer than $100 \mu \mathrm{m}$ whereas the microcrystals of $\beta C D /$ tetradecane inclusion complexes are typically shorter than $10 \mu \mathrm{m}$ [27]. Smaller $\beta C D$ microcrystals have denser packing at the $\mathrm{O} / \mathrm{W}$ interface, in turn providing better stabilization of the emulsion formed. In general, the formation of such well-defined crystalline structures may be expected in systems containing a single type of lipid, like isopropyl myristate. However, in complex systems like natural oils, well-structured crystals are not observed as the simultaneous presence of various compounds does not allow the crystals to grow [58].

In some cases, depending on the $\mathrm{CD}$ and oil type, inclusion complexation of the $\mathrm{O} / \mathrm{W}$ interphase may lead to the formation of colloidosomes or CD beads, which are
oil/CD complexes at the $\mathrm{O} / \mathrm{W}$ interface occurring at high $\mathrm{CD}$ concentration and/or longer interaction time; and $\mathbf{C}$ emulsion stabilisation with $\mathrm{CD} / \mathrm{PEG}$ hydrogel

microparticles containing the oily core and a self-forming film containing partial inclusion complexes of $\mathrm{CD}$ and triglycerides. Such behaviour is typical for emulsions containing $\alpha \mathrm{CD}$ and soybean oil [59] but may also occur in the case of both $\alpha \mathrm{CD}$ and $\beta \mathrm{CD}$ with liquid paraffin and silicone oil [60]. The properties of such beads as a delivery system are reviewed elsewhere [61, 62].

Besides natural CDs, polymeric CDs may also stabilize the emulsions. The polymeric $\beta C D$ prepared by polycondensation with epichlorohydrin under alkaline conditions $\left(M_{\mathrm{w}}\right.$ of $10^{5} \mathrm{~g} \mathrm{~mol}^{-1}$ and polydispersity of 1.5$)$ adsorbs at the $\mathrm{O} / \mathrm{W}$ interface, resulting in an elastic layer that prevents coalescence and results in se emulsions [63]. The polymer prepared by crosslinking $\mathrm{DM} \beta \mathrm{CD}$ with phenyl diisocyanate self-assembles in water to form nanoparticles with a diameter of 30-50 nm. By increasing the polymer concentration from $0.01 \%$ to $0.1 \%(\mathrm{~m} / \mathrm{m})$, primary particles assemble into larger nanogel particles with a 120 -nm diameter that show surface activity at the air/water interface. The observed surface activity of the $\mathrm{CD}$ nanogel is more pronounced than that of pure DIMEB. The CD nanogel absorbs at the O/W interface with effective saturation, forming a strongly interconnected network that results in Pickering emulsion formation, even when used at a low concentration of $0.1 \%(\mathrm{~m} / \mathrm{m})$ [64].

The type of Pickering emulsion formed is governed by the wettability of the particles formed at the $\mathrm{O} / \mathrm{W}$ interface. The particles must be partially wetted by both liquids to effectively stabilize the emulsion, or otherwise will be completely dispersed in a single phase and unable to obtain a stable emulsion. The wettability is usually characterised by the three-phase contact angle ( $\theta$, Fig. 1). For particles stabilizing the Pickering emulsion, $\theta$ is equivalent to the HLB (hydrophilic-lipophilic balance) value for surfactants [1,2]. 
Hydrophilic particles with $\theta<90^{\circ}$ favour the formation of $\mathrm{O} / \mathrm{W}$ emulsions because most of the particles are wetted by the aqueous phase of the emulsion. Such systems are usually formed when hydrophilic CD derivatives are employed as emulsion stabilizers [65]. For example, $\theta$ values for solid particles obtained by the inclusion complexation between soybean oil, squalene, isopropyl myristate, and liquid paraffin with $\beta C D$ are $58^{\circ}, 63^{\circ}, 64^{\circ}$, and $68^{\circ}$, respectively [53, 54]. On the other hand, lipophilic particles with $\theta>90^{\circ}$ favour the formation of a W/O emulsion, like complexes of soybean oil, squalene, and liquid paraffin with lipophilic cyclodextrin derivatives such as triacetyl- $\beta C D$ (TA $\beta C D)$, tripropanoyl- $\beta C D$ (TP $\beta C D)$, and tributanoyl- $\beta C D$ (TB $\beta C D)$. Their $\theta$ values range from $104^{\circ}$ to $142^{\circ}[53,54]$. Here, it must be noted that the presented $\theta$ values are only valid for given cases, as the nature of the oil used directly affects the value of $\theta$. Furthermore, the oil viscosity is a damping factor for stabilizing particles that anchor at the $\mathrm{O} / \mathrm{W}$ interface as it slows down the particle's diffusion and adsorption [1].

Another approach that may be used in the development of CD-based Pickering emulsions is the formation of stabilizing particles by inclusion complexation of some other compounds, besides the ones present in the oil-phase of the emulsion. Hu et al. prepared stabilizing nanoparticles of 60-nm diameter through inclusion complexation of short linear glucans (SLGs) with $\beta C D$ [66]. The $\theta$ of the nanoparticles can be finely tuned in the $75-15^{\circ}$ range by changing the CD to SLG ratio. Such particles facilitated preparation of Pickering emulsions of soybean oils with enhanced storage stability that have potential for applications in the food, cosmetic, and pharmaceutical fields [66]. Furthermore, inclusion complexes of $\alpha \mathrm{CD}$ and sodium salts of $n$-alkyl sulphate or sulfonate surfactants result in films at the air/ water interface of remarkable viscoelasticity [67]. The viscoelasticity of the films can be finely tuned by adjusting the bulk composition, temperature, alkyl chain length, and headgroup type, clearly demonstrating the versatility of such complexes. In addition, inclusion complexation of $\beta C D$ with Tween 20 with consequent self-assembly driven by hydrogen bonding with excessive $\beta C D$ resulted in nanoparticles that can produce stable Pickering emulsions of lavender essential oil. The optimal weight ratio of $\beta C D$ to Tween 20 appears to be 1:0.3 and provides the possibility to incorporate up to around $44 \%$ of lavender essential oil [68].

Nowadays, various novel CD derivatives with enhanced functionalities are being developed. The outer surface of CDs may be chemically modified, which provides them with amphiphilic properties. A series of amphiphilic CDs modified at their secondary face, known as skirt-shaped $\mathrm{CDs}$, decreased the Miglyol/water interfacial tension [69]. A recent example is an octadecenyl succinic acid$\beta C D$ (ODS $\beta C D$ ) derivative that was obtained thorough $\beta C D$ esterification with octadecenyl succinic anhydride in alkaline conditions [70]. The modified derivatives provide much more stable emulsions than those obtained with the parent $\beta C D$. Furthermore, they may act as a dual-function excipient by encapsulation of various antioxidants, including $\beta$-carotene and $\alpha$-tocopherol, that can enhance the oxidative stability of the formed emulsions among numerous possibilities. Notably, the inclusion complexation of antioxidants does not impair their emulsion-forming capacity with this novel $\beta C D$ derivative and, in fact, their physical stability is somewhat improved [71, 72].

\section{Preparation of CD-based pickering emulsions}

An overview of selected Pickering emulsions stabilised with CDs loaded with drugs or nutraceuticals is provided in Table 1. CD-based Pickering emulsions are usually prepared by a simple procedure. In most cases, the CDs are first dissolved/dispersed in the water phase of the emulsion, sometimes under moderate heating. Then, the inner phase of the emulsion is added, followed by sample homogenization, most often using rotor-stator type devices, operating in the $10,000-20,000 \mathrm{rpm}$ range for 3 to $5 \mathrm{~min}[26,53-55,65]$. Only in some cases, homogenization is obtained by applying lower shear stress, using vortex type devices operating at $3200 \mathrm{rpm}$ [73] or an overhead stirrer operating at $6000 \mathrm{rpm}$ [74]. In most cases, homogenization occurs at an ambient temperature.

When the emulsion contains a drug, it is usually dissolved in the oil phase $[55,73,75,77]$. Only in some cases, the drug has been added to the aqueous phase or oil/water mixture before $\mathrm{CD}$ addition [26,54]. With such parameters, the emulsion droplet size is usually broad, depending on the $\mathrm{CD}$ and oil type, their concentration, and the applied homogenization procedure.

An O/W Pickering high internal phase emulsion may be prepared using sunflower oil at an oil volume fraction of $75 \%(\mathrm{v} / \mathrm{v})$ and $\beta \mathrm{CD}$ in the concentration range of $0.5 \%-2.5 \%$ through one-step high-speed shearing procedure achieved using a rotor-stator homogenizer operating at $15,000 \mathrm{rpm}$ for $3 \mathrm{~min}$ [9].

When the Pickering emulsion is stabilised by nanoparticles formed between the $\mathrm{CD}$ and some other compound not originating from the oily phase, the nanoparticles are first prepared in the aqueous phase. Pertinent examples include nanoparticles obtained by inclusion complexation of Tween 20 or short linear glucans with $\beta \mathrm{CD}[66,68]$. The oil phase is then added to the aqueous dispersion of nanoparticles, followed by emulsification using a high-shear homogenizer.

It must be noted that currently used preparation methods do not take account into the mechanisms responsible for Pickering emulsion formation in the presence of CDs. 


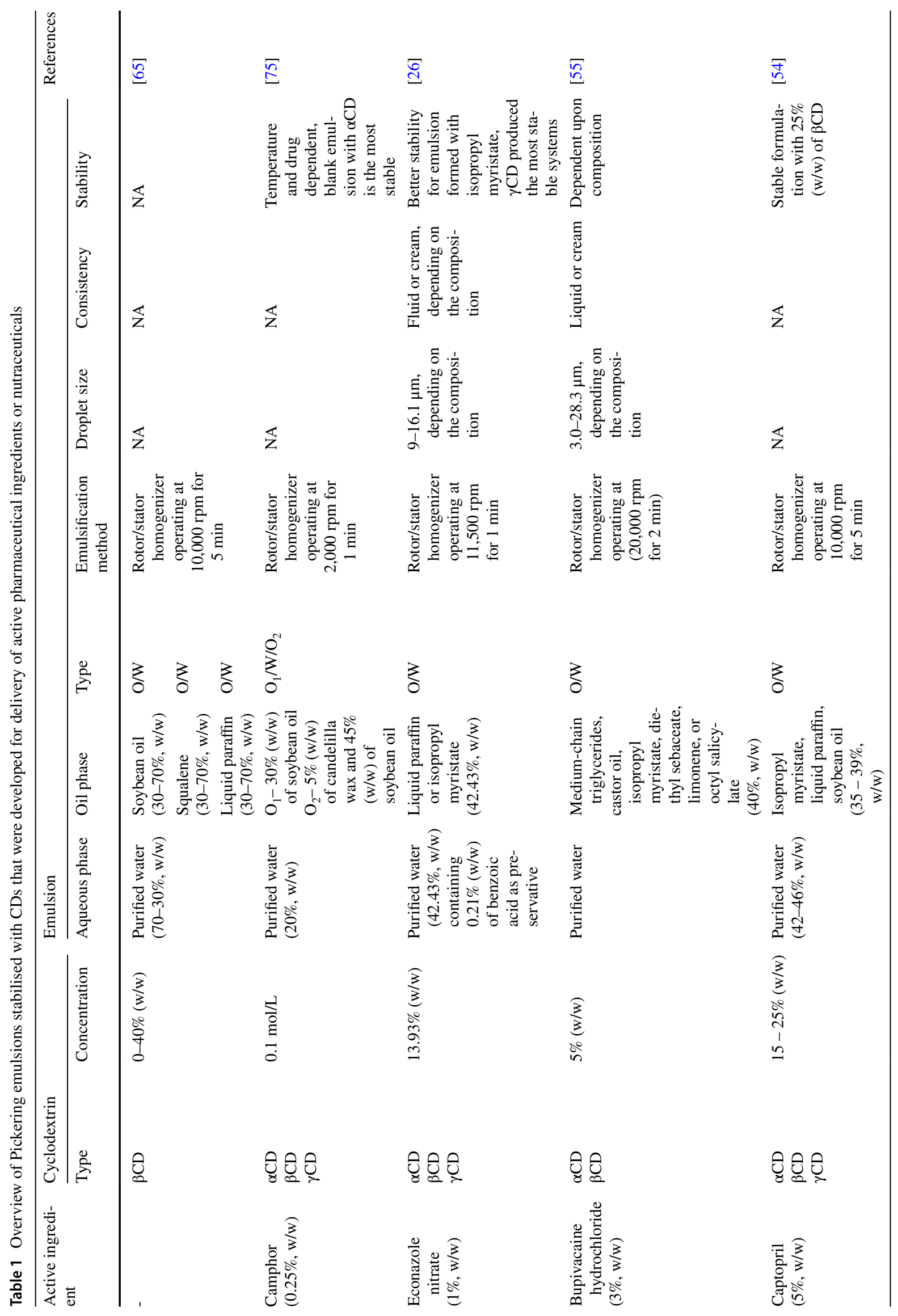




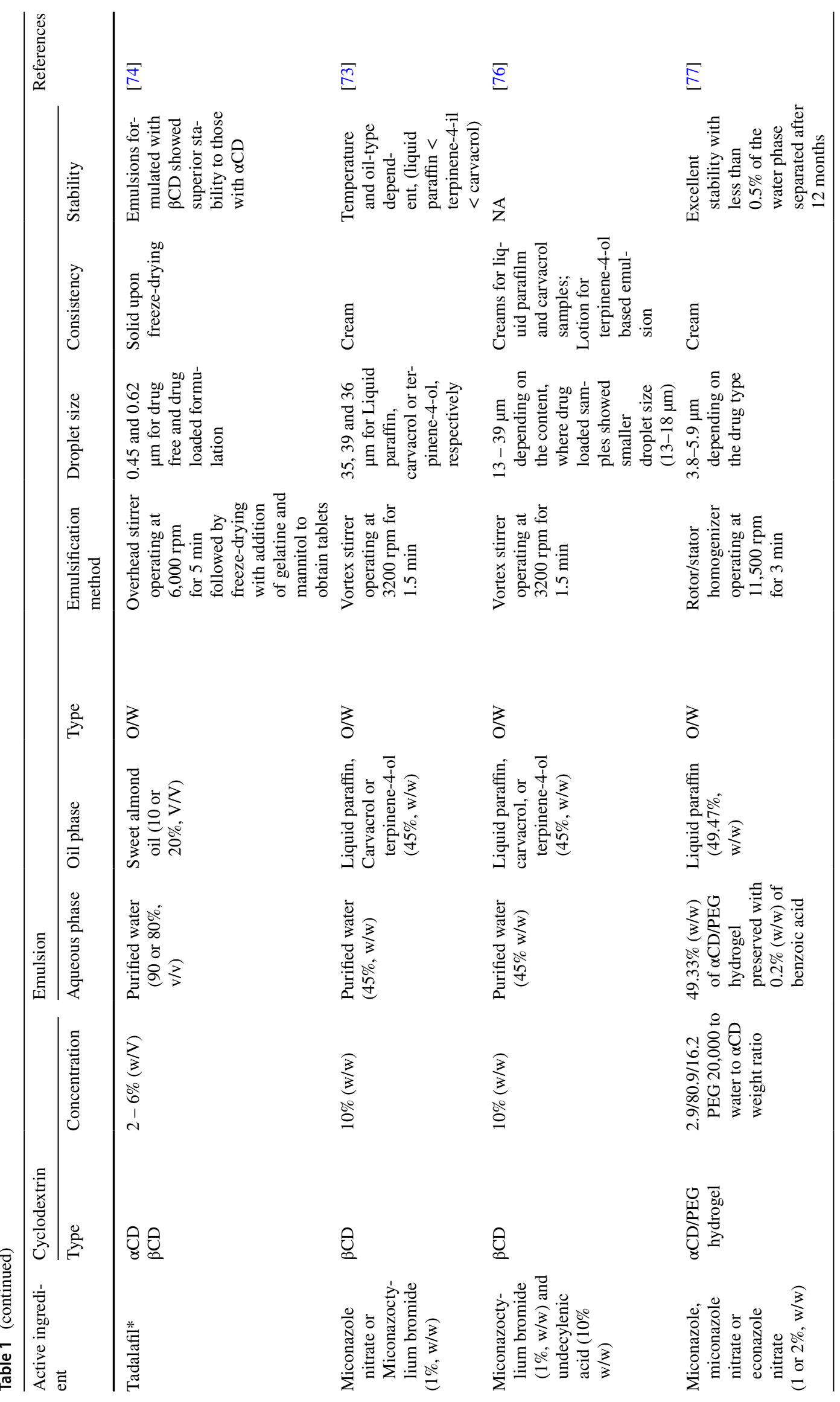




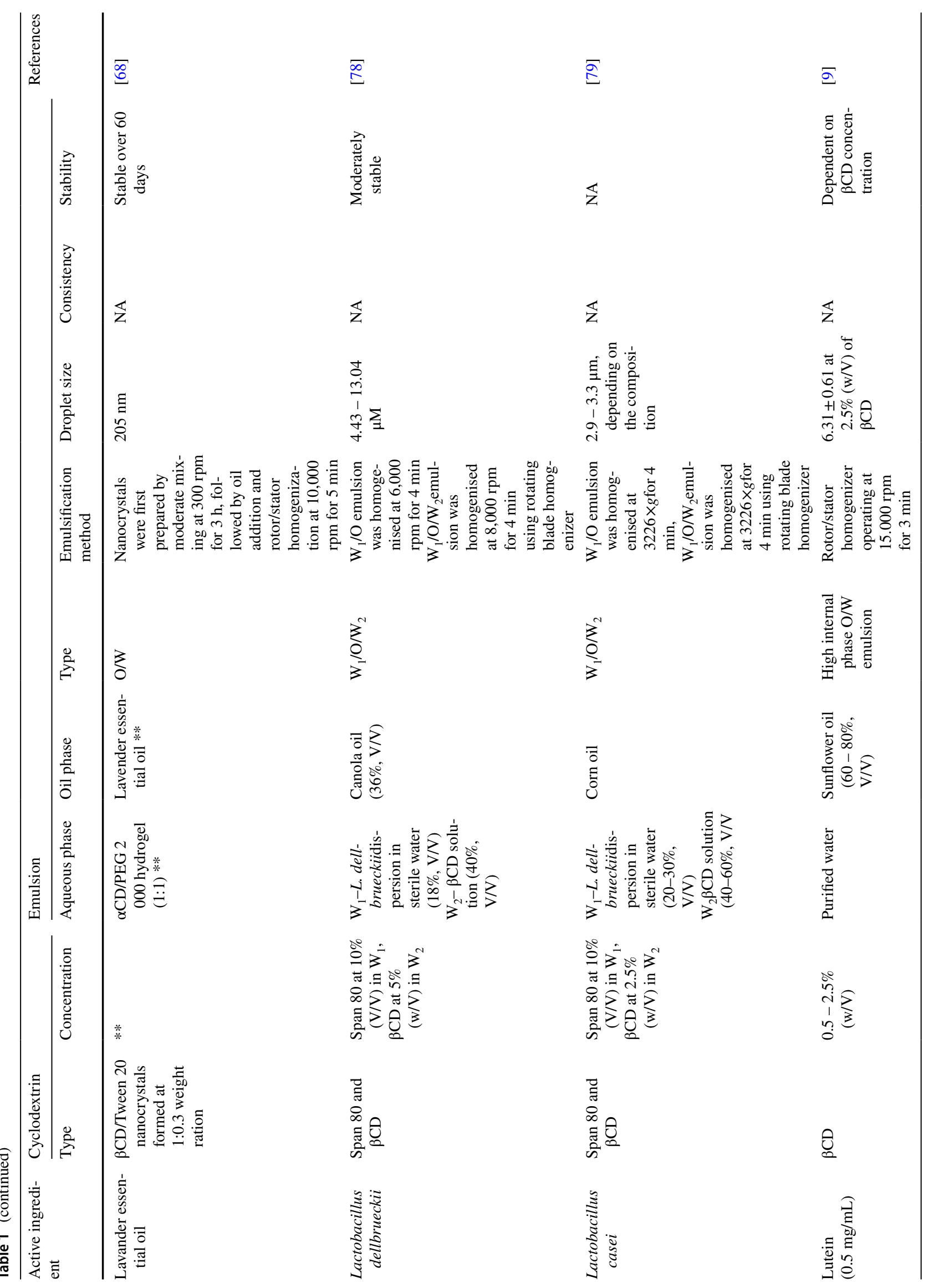


Particle formation at the $\mathrm{O} / \mathrm{W}$ interface is time-consuming, so short homogenisation procedures that are usually applied do not seem appropriate. They also cause high shear stress in the system that is necessary to disperse the oil and may oppose the formation of stabilising particles at the $\mathrm{O} / \mathrm{W}$ interface. Perhaps, the preparation of Pickering emulsions stabilised with CDs should include two or more consecutive steps. The first step must provide the optimal conditions for stabilising particle formation at the $\mathrm{O} / \mathrm{W}$ interface. The following step(s) should be directed toward the reduction of the size of emulsion droplets. In the case of Pickering emulsions and emulsions in general, this may be obtained by using rotor-stator, high pressure, ultrasonic, or microfluidic devices $[1,80]$. However, the operating parameters should be adjusted to not disturb previously formed particles by application of excessive shearing stress. Also, an increase in the sample temperature caused by homogenisation may lead to the destruction of formed particles. Perhaps, membrane emulsification, where the oil phase is pressed through a microporous membrane into the continuous phase containing CDs, would be more beneficial [81]. For the moment, such approaches are not applied in the development of CDbased Pickering emulsions, representing an unexplored area requiring further research and offering new opportunities.

\section{Stability issues of CD-based pickering emulsions}

One of the most significant advantages of Pickering emulsions is their high physical stability. In general, particles with $0.01-10-\mu \mathrm{m}$ diameters and an intermediate $\theta$ attach strongly to the $\mathrm{O} / \mathrm{W}$ interface with high detachment energies. Such surface coatings prevent coalescence of the dispersed phase, resulting in Pickering emulsions with superior stability to emulsions stabilised by surfactants $[26,80]$. However, such general performance claims cannot be directly related to Pickering emulsions stabilised by CDs because it must be considered that particles containing CDs are obtained by consecutive association phenomena, i.e. inclusion complexation and complex precipitation at the $\mathrm{O} / \mathrm{W}$ interface. As both processes are reversible, several factors may affect the capacity of CDs to stabilize the emulsion and even result in complete phase separation.

Some early studies showed that temperatures higher than $50{ }^{\circ} \mathrm{C}$ negatively affect the inclusion complexation of liquid paraffin components with $\beta C D$, resulting in a lack of emulsification, while efficient emulsification can be obtained at a lower temperature [82]. Similarly, complete dissolution of tetradecane $/ \alpha \mathrm{CD}$ microcrystals occurs at temperatures higher than $80{ }^{\circ} \mathrm{C}$, but upon cooling they recrystallise in the form of spherical structures [28]. In the case of particles stabilizing emulsions of olive oil and $\alpha \mathrm{CD}$, their dissolution 
started at temperatures above $30{ }^{\circ} \mathrm{C}$ when the oil content in the emulsion was greater than $25 \%(\mathrm{~m} / \mathrm{m})$ [58]. Those examples show that the temperature at which Pickering emulsions based on CDs are prepared and stored should be carefully considered.

Regarding particle stabilizers of Pickering emulsions, parameters like wettability, size and shape, concentration, surface roughness, and charge are crucial considerations for emulsion formation and stability [1, 2, 80]. In general, the size of the stabilizing particles should be at least one order of magnitude smaller than the targeted size of emulsion droplets. The smaller size of stabilizing particles accounts for the formation of Pickering emulsions with smaller emulsion droplets, thus showing higher physical stability.

For a series of Pickering emulsions of octanol, decane, and toluene stabilised with $10 \%$ of $\beta C D$, the diameter of emulsion droplets and the size of stabilizing particles were $15.14 / 1.35 \mu \mathrm{m}, 7.22 / 1.32$ and $12.58 / 2.98$, respectively [83]. The most stable emulsion was the one with decane, showing a volume fraction of the emulsion phase that was greater than $90 \%$ over a longer period. Besides particle size, the most pronounced decrease in interfacial tension and relatively high $\theta$ was observed for a $\beta C D /$ toluene system, which accounted for the comparatively enhanced physical stability of this sample [83]. These findings motivate that a general design principle of CD-stabilised Pickering emulsions should be reducing the size of the formed solid particles, as particles smaller than $2 \mu \mathrm{m}$ are not affected by gravity. Furthermore, nanoscale Pickering emulsions have also been reported $[68,84]$. In the case of nanoparticles having $\theta$ in the range of $30-150^{\circ}$, the thermal energy of Brownian motion is several orders of magnitude lower than the desorption energy, which facilitates their irreversible adsorption at the $\mathrm{O} / \mathrm{W}$ interface [85]. Currently, the exact parameters affecting the size of the forming particles at the $\mathrm{O} / \mathrm{W}$ interface in systems containing oils and CDs are not known and should be further investigated. It may be presumed that the type and concentration of both the oil and CD, as well as the stirring rate, $\mathrm{pH}$, and temperature at which the emulsion is prepared may be significant factors.

Regarding the shape of the particles, the first Pickering emulsions were constructed using spherical particles, but stabilization has also been obtained with different nonspherical particles, like rods, fibres, and cubes. It is recognised that deformable particles cover the O/W more efficiently, accounting for enhanced Pickering emulsion stability. In this sense, microgels are particularly efficient [1]. As already mentioned, polymeric CD derivatives stabilize emulsions more efficiently than parent derivatives, owing to their enhanced flexibility [63, 64].

Information about the shape of the formed particles in Pickering emulsions stabilised by CDs is scarce. Mathapa and Paunov demonstrated that different particle shapes occur during inclusion complexation of tetradecane with $\alpha \mathrm{CD}$ and $\beta C D$ [27, 28]. At the same concentration (10 mM), $\alpha \mathrm{CD}$ formed microrods up to $100 \mu \mathrm{m}$ long that were stacked into lamellar structures, while in the case of $\beta C D$, shorter crystals (up to $10 \mu \mathrm{m}$ ) were observed and did not form lamellar structures. The authors proposed that the microrods are formed by threading the CD molecule through the tetradecane chain. Such structures assemble into nano- and microrods over time. This process is guided by hydrogen bonding. The formation of $\alpha \mathrm{CD} /$ tetradecane microrods was fast, resulting in the complete coverage of the oil droplet with microcrystals after $12 \mathrm{~min}$, while the process was much slower in the case of $\beta C D$. Although $\alpha \mathrm{CD} /$ tetradecane microrods produced a higher decrease of interfacial tension than those with $\beta C D$, higher emulsion stability was observed in the latter case, as smaller $\beta \mathrm{CD} /$ tetradecane microparticles adsorb and pack tightly on the $\mathrm{O} / \mathrm{W}$ interface, which generates a steric barrier that prevents droplets coalescence and ensures effective emulsion stabilization [27]. By contrast, long and rigid $\alpha \mathrm{CD} /$ tetradecane microrods cannot effectively pack when adsorbed at the $\mathrm{O} / \mathrm{W}$ interface. This increases the likelihood of exposure of bare oil patches on the droplets, leading to coalescence and low emulsion stability. $\gamma \mathrm{CD}$ does not form microcrystals at the $\mathrm{O} / \mathrm{W}$ interface as its central cavity is probablytoo large to hold on to the tetradecane chain. Other factors affecting the formation and structure of $\mathrm{CD} /$ tetradecane microcrystals are temperature, $\mathrm{pH}$, and the presence of chaotropic agents. As already discussed, elevated temperature promotes the degradation of $\mathrm{CD} /$ toluene microcrystals due to the breakdown of hydrogen bonds and de-threading produced by elevated kinetic energy in the system. The $\alpha \mathrm{CD} /$ tetradecane microrods form preferably at neutral $\mathrm{pH}(7.16)$, in which condition the hydroxyl groups are not disturbed and fully participate in the cooperative hydrogen bonding that is necessary for enhanced threading and growth of the microrods. By contrast, $\beta \mathrm{CD} /$ tetradecane microrods are preferably formed at low $\mathrm{pH}$ (1.98), which is necessary to disrupt the intermolecular hydrogen bonds in the $\beta C D$. The free $\beta C D$ hydroxyl groups can participate in inter-cooperative hydrogen bonding that results in an increased rate of threading and subsequent precipitation. Finally, the presence of a chaotropic agent like urea promotes the disruption of the microrods [28]. In the case of more pharmaceutically acceptable oils, like medium-chain triglycerides, castor oils, isopropyl myristate, diethyl sebacate, and octyl salicylate, rod-like crystals and large cubic crystals are observed in the case of complexes with $\alpha \mathrm{CD}$, while cubic crystals occur mainly in the case of complexes with $\beta C D$ [55]. Conversely, Badr-Eldin et al. showed that the particles formed with sweet almond oil and $\alpha \mathrm{CD}$ were smaller and shorter than those formed with $\beta C D$ [74]. Moreover, emulsions containing 10 and $20 \%$ of the oil phase stabilised with $\alpha C D$ contained smaller droplets, ranging from 0.37 to $0.97 \mu \mathrm{m}$, and were 
less stable than the corresponding samples, stabilised with the same concentration of $\beta \mathrm{CD}$, containing larger droplets in the range from 0.68 up to $2.43 \mu \mathrm{m}$ [74]. It seems that, besides the shape and size of the stabilising particles, their adsorption energy at the $\mathrm{O} / \mathrm{W}$ interface has a significant impact on Pickering emulsion stability. The free energy of adsorption, $\Delta G_{\mathrm{d}}$, represents the energy required to remove a spherical particle of radius $r$ and three-phase contact angle $\theta$ from an $\mathrm{O} / \mathrm{W}$ interface with an interfacial tension of $\gamma_{\mathrm{OW}}$ and is defined by the following Eq. [1]:

$\Delta G_{d}=\pi r^{2} \gamma_{O W}(1-|\cos \theta|)^{2}$

It may be concluded that the solid particles formed between the sweet almond oil and $\beta C D$ cause a more significant reduction in the interface tension and/or have a higher $\theta$ than those with $\alpha \mathrm{CD}$ and accordingly form Pickering emulsions with enhanced stability. However, as Badr-Eldin et al. [74] did not measure the $\mathrm{O} / \mathrm{W}$ interfacial tension and $\theta$, this assumption cannot be supported by the experimental data and requires future testing for validation.

The concentration of the stabilizing particles is another important parameter as it directly affects their coverage at the $\mathrm{O} / \mathrm{W}$ interface. In general, a high concentration of the stabilizing particles is desired, as it increases the surface coverage of emulsion droplets and facilitates the formation of a network structure, which is advantageous for reducing the size and improving the stability of the emulsion $[2,85]$. This, in general, requires the use of a relatively high $\mathrm{CD}$ concentration, at least in the case of parent $\mathrm{CD}$ derivatives. In many cases, the parent $\beta C D$ is added to the emulsions in concentrations exceeding its aqueous solubility $[26,53-55$, $73,83]$. Laurent et al. suggested that an excess of $\beta C D$ in the aqueous phase of the emulsion acts as a reservoir during and after the emulsification process, providing the source of free $\beta \mathrm{CD}$ that is available for complexation with the lipid components of the oil phase [82]. This contributes to the formation of the stabilizing particles at the $\mathrm{O} / \mathrm{W}$ interface, providing a sufficient coverage of the dispersed droplets. When the interface is fully saturated, the formed oil/CD particles increase the viscosity of the aqueous phase of the emulsion, thus further stabilising the system, as already discussed above in other examples.

The addition of surfactants may also have a wide range of effects on the CD stabilization ability of Pickering emulsions. Li et al. investigated the effect of Tween 80 and soybean lecithin (SL) on the stability of medium-chain triglyceride (MCT) emulsions stabilised with $\alpha \mathrm{CD}$ [86]. In the absence of the surfactants, an emulsion containing a low oil fraction $\left(\varphi_{O}=0.03\right)$ was unstable while that containing a higher oil phase $\left(\varphi_{O}=0.2\right)$ appeared stable. As both formulations contained a similar concentration of $\alpha \mathrm{CD}$ (i.e. 5 and $6 \%$, respectively) and had a comparable size of the emulsion droplets (mean spherical diameter of 18.6 and $22.0 \mu \mathrm{m}$, respectively), better stability of the emulsion containing the higher volume of the oil phase was attributed to its higher viscosity. The addition of $0.5 \%$ Tween 80 enhanced the stability of the emulsion with a low oil fraction. This was attributed to the synergistic effect of $\alpha \mathrm{CD} / \mathrm{MCT}$ and Tween 80 and was explained by several phenomena. First, the interaction of $\alpha C D$ and Tween 80 and consequent assembly of the complexes into bilayers stabilised by hydrogen bonds increased the viscosity of the emulsion viscosity. Furthermore, the addition of Tween 80 decreased the zeta potential of the system (from $-32.2 \mathrm{mV}$ to $-40.7 \mathrm{mV}$ ), providing additional electrostatic stabilization. Finally, Tween 80 also caused a further reduction in the interfacial tension (from 29.62 to $16.47 \mathrm{mN} \mathrm{m}^{-1}$ ). In the case of other surfactants, the effects are not straightforward. The effect of SL on CDbased emulsion stability is concentration-dependent. At $0.1-1.0 \%$, SL impaired the stability of emulsions containing a high oil fraction, which was caused by the replacement of $\alpha \mathrm{CD} / \mathrm{MCT}$ with $\alpha \mathrm{CD} / \mathrm{SL}$ particles at the interface. At high SL concentrations (3.0\%-5.0\%), emulsions were stable against coalescence and phase separation, which was caused by a significant drop in the interfacial tension (from 23.09 to less than $2.00 \mathrm{mM} \mathrm{m}^{-1}$ ) [86]. This example confirms that inclusion complexation between CDs and surfactants should be carefully considered in the case of CD-based Pickering emulsions, as it may provide a window of opportunity to enhance emulsion stability through changes in viscosity and interfacial tension, by using physiologically acceptable surfactants which alone cannot produce sufficiently stable emulsions. For example, $\beta C D$ enhanced the stability of a sunflower oil emulsion $\left(\varphi_{O}=0.20\right)$ prepared with $4 \%(\mathrm{w} / \mathrm{w})$ citric acid esters of fatty acids as an emulsifier (Citrem ${ }^{\circledR}$ $3307)$. At a $1: 1$ (w:w) ratio with $\mathrm{Citrem} \circledast, \beta C D$ decreased the droplet size of the resulting emulsion (from $4.3 \pm 0.5$ to $2.1 \pm 0.8 \mu \mathrm{m}$ ) and simultaneously increased its viscosity (from $26.1 \pm 0.9$ to $33.8 \pm 0.4 \mathrm{mPa} \mathrm{s}^{-1}$ ). All of these modulations in turn enhanced storage stability while decreasing, to some extent, the oxidative stability of the emulsion, which required the addition of antioxidants as well [87].

Increasing the emulsion viscosity is another approach that may oppose the coalescence of dispersed oily droplets, thus enhancing stability [85]. The use of a $\alpha \mathrm{CD} / \mathrm{PEG}$ hydrogel appears particularly suitable for the development of stable Pickering emulsions [77]. This hydrogel is formed by heating PEG 20,000 , water and $\alpha \mathrm{CD}$ in a weight ratio of 2.9:80.9:16.2 at $80{ }^{\circ} \mathrm{C}$. After cooling at $3{ }^{\circ} \mathrm{C}$, the homogenised mixture results in a stable, transparent hydrogel. In this case, the formation and structure of the $\alpha \mathrm{CD} / \mathrm{PEG}$ hydrogel may also be explained by the colloidal tectonics concept [56, 88]. As shown in Fig. 2 C, the columnar CD domains (crystallites) act as physical cross-links between the polymer chains not included, leading to the formation of 
a supramolecular hydrogels that provides a good platform to obtain Pickering-like emulsions [56]. Simple addition of liquid paraffin $\left(\varphi_{\mathrm{O}}=0.5\right)$ followed by homogenization at $11,500 \mathrm{rpm}$ for 3 min yields a stable emulsion of the $\mathrm{O} / \mathrm{W}$ type (Fig. 2). Even when loaded with azole antifungal drugs, at 1 and $2 \%$ concentrations, the emulsions showed remarkable stability over 12 months of storage [77].

Nanoemulsions as systems with droplet sizes of the dispersed phase in the range of $20-500 \mathrm{~nm}$, have evolved as a robust carrier for the delivery of a wide range of drugs with poor aqueous solubility and provide attractive features such as enhanced loading capacities, long-term stability, increased bioavailability, and controlled release of loaded drugs [89]. CDs canform robust Pickering nanoemulsions with high loading capacity in two different synergistic ways. For example, Tween 20/BCD nanoparticles, formed during nanoemulsion preparation by inclusion complexation of Tween 20 with $\beta C D$ followed by hydrogen bonding driven assembly with an excessive amount of $\beta C D$, adsorbed at the $\mathrm{O} / \mathrm{W}$ interface, which allowed Pickering nanoemulsion preparation with nanodroplets of 205-nm diameter and encapsulated up to $44.42 \%$ of lavender essential oil. In addition, an $\alpha \mathrm{CD} / \mathrm{PEG} 20 \mathrm{kDa}$ gel formed a three-dimensional network between nanodroplets, which helped to sustain system stability by resisting coalescence. With such an approach, the stability of Pickering nanoemulsions was extended from 15 to 60 days [68].

\section{Effect of drug addition on CD-based Pickering emulsion formation and stability}

The addition of a drug may have a destabilising effect on Pickering emulsions containing CDs due to competitive interactions with lipid components from the oil phase for inclusion complexation. Such effects were observed in the case of $\mathrm{O} / \mathrm{W} / \mathrm{O}$ multiple emulsions loaded with camphor [75]. The inner oily phase consisted of $30 \%$ (w/w) of soybean oil dispersed in $20 \%(\mathrm{w} / \mathrm{w})$ of $0.1 \mathrm{M} \alpha \mathrm{CD}, \beta \mathrm{CD}$, or $\gamma \mathrm{CD}$ aqueous solution. The outer oily phase was prepared with $5 \%(\mathrm{w} / \mathrm{w})$ of candelilla wax dissolved in $45 \%(\mathrm{w} / \mathrm{w})$ of soybean oil. Camphor was loaded in the inner oil phase at $0.47 \mathrm{mM}$ concentration. The stability of the as-prepared emulsions was affected by the type of CD used, storage temperature, and the presence of camphor. The $\alpha \mathrm{CD}$ and $\beta C D$ emulsions without camphor were considered stable, but their stability was disturbed by the addition of camphor. $\mathrm{X}$-ray powder diffraction (XRPD) analysis showed different crystalline structures of solid particles in the emulsions with and without camphor. The authors assumed that the affinity of camphor for inclusion complexation with CDs $\left(K_{\mathrm{s}}\right.$ are 80, 430 , and $370 \mathrm{M}^{-1}$ for $\alpha \mathrm{CD}, \beta \mathrm{CD}$, and $\gamma \mathrm{CD}$, respectively) was strong enough to induce the destabilization of emulsions by competing with the complexation of fatty acid residues of soybean triglycerides, which were insufficiently stable. As a possible approach to overcome such limitations, the authors suggested the use of $\alpha \mathrm{CD}$ in the development of Pickering emulsions. $\alpha \mathrm{CD}$ usually has a low affinity for inclusion complexation of high molecular-weight drugs [75].

However, some other authors demonstrated that stable emulsions may be obtained when the drug concentration in the oily phase is relatively low. In such systems, CD complexation of the components from the oil phase is dominant, as they are prevalent in the system with respect to the drug [26]. Leclercq and Nardello-Rataj prepared a series of Pickering emulsions containing isopropyl myristate of liquid paraffin as the oil phase $\left(\varphi_{O}=0,4243\right)$ that was stabilised with $13.39 \%$ of $\alpha \mathrm{CD}, \beta \mathrm{CD}$, or $\gamma \mathrm{CD}$. All formulations contained $0.21 \%$ of benzoic acid as a preservative and $1 \%$ of econazole nitrate as an active ingredient. Such emulsions showed optimal viscosity and were physically stable after storage at $60{ }^{\circ} \mathrm{C}$. In general, the stability of emulsions was determined simultaneously by $\mathrm{CD}$ type and oil type. Emulsions formulated with isopropyl myristate were more stable than those with liquid paraffin and the most stable emulsions were obtained with $\gamma \mathrm{CD}$ [26]. The authors did not prepare and evaluate emulsions without the drug, but all CD-stabilised emulsions with econazole were suitable for dermal applications.

Hu et al. prepared a series of emulsions containing $40 \%$ $(\mathrm{w} / \mathrm{w})$ of the oil phase, $5 \%(\mathrm{w} / \mathrm{w})$ of $\mathrm{CD}$, and $3 \%(\mathrm{w} / \mathrm{w})$ of bupivacaine using different oils and CDs [55]. MCTs and diethyl sebacate formed stable emulsions only with $\alpha \mathrm{CD}$ as its central cavity size is appropriate to tightly fit their alkyl chains. Surprisingly, the emulsion formed with $\alpha C D$ isopropyl myristate, another linear chain compound, became phase-separated after only one day. The authors suggested that, as isopropyl myristate contains only one ester group, the hydrogen bonding was not sufficient to stabilize the complex at the $\mathrm{O} / \mathrm{W}$ interface while, in the case of diethyl sebacate, a compound containing two ester groups, hydrogen bonding was more pronounced and thus suitable to stabilize the emulsion. Castor oil was efficiently emulsified by both $\alpha C D$ and $\beta C D$, which was attributed to the presence of the hydroxyl group on the alky tail of the castor oil. Hydrogen bonding of this hydroxyl group with those of the CD molecule reinforced the complexes formed at the $\mathrm{O} / \mathrm{W}$ interface, resulting in stable Pickering emulsions. Limonene and octyl salicylate contain a hexa-carbon ring in their structure and should interact more preferably with $\beta C D$. However, a stable emulsion was only obtained with octyl salicylate and $\beta C D$ while, in emulsions formulated with limonene, separation occurred after only one minute. Most of the emulsions formed showed mean particle sizes in the range of 1.9-5 $\mu \mathrm{m}$ and low polydispersity that may be attributed to the intense sample homogenization conditions that were used, i.e. 
$20,000 \mathrm{rpm}$ for $5 \mathrm{~min}$. The exception was the emulsion of diethyl sebacate and $\alpha \mathrm{CD}$, which was polydisperse with a mean particle size of $28.3 \mu \mathrm{m}$ [55]. In these cases, the presence of the drug was not recognised as a destabilizing factor with respect to emulsion structure. In fact, it seems that the drug presence may aid in emulsion formation. Leclerq et al. used $\beta C D$ to develop Pickering emulsions of liquid paraffin, carvacrol, and terpinene-4-ol as the base and aimed to increase the antimicrobial activity of miconazole nitrate and miconazoctylium bromide [73]. In all cases, the water to oil to CD weight ratio was $45 / 45 / 10$ and resulted in a white emulsion of the $\mathrm{O} / \mathrm{W}$ type with average droplet sizes of 35 , 39 , and $36 \mu \mathrm{m}$, respectively. SEM analysis revealed that the stabilizing particles in the case of liquid paraffin were granular solids, while those with carvacrol and terpinene-4-ol were of lamellar shape. The emulsions were stable at human body temperature of $37^{\circ} \mathrm{C}$ for more than two weeks, while at an elevated temperature of $60{ }^{\circ} \mathrm{C}$, the samples showed instability after only $6 \mathrm{~h}$. The destabilization mechanism was studied by multiple light scattering. For liquid paraffin, a creaming process was detected that was coupled with a coalescence phenomenon, while for carvacrol and terpinene4-ol, only coalescence was observed. The addition of a drug molecule at $1 \%(\mathrm{w} / \mathrm{w})$ had distinct, drug-specific effects on the emulsion droplet size. In the case of miconazole nitrate, the droplet size remained the same as in emulsions without the drug, while in the case of miconazoctylium bromide, a reduction in the droplet size down to the $17-26 \mu \mathrm{m}$ range was observed, indicating that miconazoctylium bromide may interact with the $\mathrm{O} / \mathrm{W}$ interface stabilised by $\beta \mathrm{CD} /$ oil particles. Drug addition did not affect the shear viscosity, regardless of its type [73]. However, it should be noted that inclusion complexation of miconazole nitrate with $\beta C D$ is $\mathrm{pH}$-dependent and the $K_{\mathrm{s}}$ of the complexes formed was relatively low, decreasing from $97 \mathrm{M}^{-1}$ at $\mathrm{pH} 6$ down to $39 \mathrm{M}^{-1}$ at $\mathrm{pH} 9$ [90]. On the other hand, miconazoctylium bromide alone can form emulsions, but they are of limited stability [73]. The presented examples clearly show that the drug concentration and, in particular the structural features of the drug, should be carefully evaluated when developing Pickering emulsions stabilised with CDs.

\section{Rheological and textural features of CD-based Pickering emulsions}

The rheological properties of CD-based Pickering emulsions are related to their microstructure and are crucial for understanding the physical stability of the emulsion during processing and storage. Furthermore, rheological features determine the emulsion quality and functionality, providing acceptable sensory characteristics and spreadability of the formulation during application at the skin or mucosal surfaces and controlling drug release, which determines the therapeutic potential of such dosage forms [91].

In general, Pickering emulsions stabilised by CDs show viscoelastic rheological behaviour, exhibiting high viscosity at low shear stress and low viscosity at high shear stress $[26,73,77]$. This is particularly important for topical drug administration, providing highly viscous formulations during storage (ensuring product stability) and low viscosity when applied to skin (contributing to comfort during product application). Moreover, CD-based Pickering emulsions are thixotropic, recovering their viscosity after the product is applied which enables controlled drug delivery. The thixotropy of these emulsions indicates the presence of a threedimensional network structure of interconnected clusters that are formed between oil droplets and stabilising particles [26].

The consistency of CD-stabilised Pickering emulsions is dependent on both the $\mathrm{CD}$ and oil type and concentration. For example, $\alpha C D$-stabilised Pickering emulsions of MCTs, castor oil, and dietyl sebacate $(5 \% \mathrm{w} / \mathrm{w} \mathrm{CD}, 40 \% \mathrm{w} / \mathrm{w}$ oil phase) appeared as liquidlotions, while those containing the same amount of octylsalicilate and $\beta C D$ appeared as a cream [55]. The texture of Pickering emulsions containing liquid paraffin or isopropyl myristate as the oil phase $\left(\varphi_{O}=0.4243\right)$ and parent CDs $(13.93 \% \mathrm{w} / \mathrm{w})$ varied from fluid to cream, depending on both the oil and CD type [26]. Pickering emulsions stabilised with $\alpha \mathrm{CD} / \mathrm{PEG} 20,000$, containing around $50 \%(\mathrm{w} / \mathrm{w})$ of liquid paraffin as the oil phase, all appeared as creams, regardless of the type and concentration of the loaded drug [77]. The viscosity recorded in the high-shear region, ranging from $10^{2}$ to $10^{3} \mathrm{~s}^{-1}$, may be used to predict the spreadability of the formulation on skin surfaces. In the case of Pickering emulsions stabilised by $\alpha \mathrm{CD} / \mathrm{PEG} 20,000$ hydrogel, the viscosity remains below $2 \mathrm{~Pa} \mathrm{~s}$, indicating its suitability for topical skin applications [77]. More precisely, the viscosities of such emulsions loaded with econazole are between the values obtained by commercially available products (Micatin ${ }^{\circledR}$ cream and Pevaryl $₫$ cream, respectively). However, previously mentioned CD-stabilised Pickering emulsions containing liquid paraphing or isopropyl myristate showed higher rubbing resistance than the Pevaryl ${ }^{\circledR}$ cream but remained in the suitable range for dermal administration [26]. The dependence of the shear viscosity on CD type is not straightforward and it seems to be primarily related to the droplet size of the formed Pickering emulsions. In general, low shear viscosity is observed for emulsions with very fine droplets. It is likely that the emulsions with large droplet sizes are more viscous as a lower concentration of the $\mathrm{CD} / \mathrm{oil}$ inclusion complexes is needed to saturate the $\mathrm{O} / \mathrm{W}$ interface. The remaining insoluble particles formed in the system create a complex three-dimensional structure that increases the shear viscosity of the samples. In the case of emulsions with less oily droplets, the situation is opposite [26], 
i.e. the presence of the drug does not seem to affect the shear viscosity of CD-based Pickering emulsions [73, 77].

In the case of Pickering emulsions stabilised with SLG/ $\beta C D$ nanoparticles, the apparent viscosity of the emulsions increased over the whole shear rate range $\left(0.1-100.0 \mathrm{~s}^{-1}\right)$ as a function of increased $\beta C D$ proportion in the stabilising nanoparticles, applied nanoparticle concentration, and oil phase fraction. Shear-thinning behaviour was also observed, indicating deflocculation of the oil droplets in the emulsions. The magnitudes of $G^{\prime}$ (storage modulus) values were higher than those of $G^{\prime \prime}$ (loss modulus) values for all fabricated samples, suggesting a typical gel-like structure. Moreover, the $G^{\prime}$ and $G^{\prime \prime}$ values were independent of the oscillatory shear frequency. The increasing trend of $G^{\prime}$ and $G^{\prime \prime}$ with respect to the tested parameters corresponds to the enhanced gel strength, reflecting the superior physical stability of the emulsions formed [66]. Such rheological behaviour contrasts with that observed for Pickering emulsions formed by direct inclusion complexation of CDs and oil components [53, 57, 65, 92]. In the latter cases, variations in the $G^{\prime}$ and $G^{\prime \prime}$ values as a function of the shear frequency were observed and the systems showed liquidlike behaviour $\left(G^{\prime}<G^{\prime \prime}\right)$ in the low-frequency and solid-like behaviour $\left(G^{\prime}>G^{\prime \prime}\right)$ in the high-frequency regions and such emulsions appeared less stable in general.

High internal-phase Pickering emulsions of sunflower oil stabilised with $\beta C D$ presented somewhat different rheological behaviour. The rheological properties of emulsions are typically determined by the continuous phase, however, in the case of these emulsions, the distance between oil droplets was reduced and the stabilising particles had a significant influence on the corresponding rheological properties. In the strain sweep test, both the $G^{\prime}$ and $G^{\prime \prime}$ values of the emulsions prepared at different $\beta C D$ concentrations $(0.5-2.5 \%$, w/w) were stable at first and then gradually decreased. In the linear viscoelastic region $(0.1-100 \mathrm{~Hz})$, the $G^{\prime}$ values were superior to the corresponding $G^{\prime \prime}$ values, displaying elastic-like characteristics. Both $G^{\prime}$ and $G^{\prime \prime}$ values were $\beta C D$ concentrationdependent over the entire frequency range, indicating that the gel strength of the formed high internal-phase Pickering emulsions was positively related to the $\beta C D$ concentration. In all cases, the apparent viscosities of the emulsions decreased with increasing shear rate and the formulation developed with $2.5 \%$ (w/w) $\beta C D$ exhibited the highest apparent viscosity over the entire shear rate range. This corresponds to the most compact microstructure and the strongest mechanical performance of such high internal-phase emulsions [9].

\section{Functionality of CD-based Pickering emulsions}

In most cases (Table 1), CD-stabilised Pickering emulsions have been developed as semisolid bases for topical administration of drugs, mainly azole antifungals, to the skin $[26,73,77]$. The emulsions formed are usually of the $\mathrm{O} / \mathrm{W}$ type. Drug release from the Pickering emulsions, in general, is prolonged as the solid particle layer at the $\mathrm{O} / \mathrm{W}$ interface forms a shell that controls the release of drugs entrapped in the oily particles [2]. Prolonged drug release has also been observed for CD-based Pickering emulsions loaded with bupivacaine, in which case less than $30 \%$ of the loaded drug was released after $48 \mathrm{~h}$ [55]. In this example, the type of $\mathrm{CD}(\alpha \mathrm{CD}$ or $\beta C D$ at $5 \% \mathrm{w} / \mathrm{w})$ or the oil type (MCTs, castor oil, diethyl sebacate, or octyl salicylate; $\varphi_{\mathrm{O}}=0.4$ ) did not significantly affect the observed drug release rate, which can be rationalized by two factors. First, stabilizing particles formed by CD complexation of oil-phase components formed a solid film consisting of tightly packed particles that covered the droplet surface. Second, the drug solubility in water $(0.14 \mathrm{mg} / \mathrm{mL})$ and selected oils (ranging from $41.9 \mathrm{mg} / \mathrm{mL}$ up to $99.4 \mathrm{mg} /$ $\mathrm{mL}$ ) was different, favouring drug partitioning into the oil phase of the emulsion. As such, a tight particulate film at the $\mathrm{O} / \mathrm{W}$ interface and dominant partitioning of the drug into the oil phase of the emulsion synergistically reduced the bupivacaine release rate.

The cumulative amount of drug permeation across a porcine skin model showed the following order: octyl salicylate/ $\beta C D$ emulsion $>$ diethyl sebacate $/ \alpha C D$ emulsion $=\mathrm{MCT} /$ $\alpha \mathrm{CD}$ emulsion $>$ castor oil $/ \alpha \mathrm{CD}$ emulsion $=$ castor oil $/ \beta C D$ emulsion. Moreover, the cumulative extent of drug permeation in the case of the emulsion formulated with octyl salicylate was significantly higher than for the other formulations, indicating that octyl salicylate could substantially enhance skin penetration of bupivacaine. However, a rabbit skin irritation test showed that this formulation caused the most serious irritation of all formulations [55]. As topical bupivacaine is used for local anaesthesia, the formulation needs to target the nerves in the dermal layer without favouring systemic drug absorption. Hence, the drug amount retained in the skin is considered to be a more appropriate factor to assess the anaesthetic efficiency of CD-stabilised Pickering emulsions. From that point of view, emulsions formulated with diethyl sebacate and $\alpha \mathrm{CD}$ appeared to be the most efficient. As oils are known skin permeation enhancers, the authors compared the skin permeability of the drug released from a plain oil solution and from CD-stabilised Pickering emulsions. It was demonstrated that the bupivacaine permeation was more efficient in the case of Pickering emulsions, suggesting a synergistic effect of CDs on skin permeability [55]. 
Leclercq and Nardello-Rataj demonstrated that, for Pickering emulsions formulated with liquid paraffin or isopropyl myristate as the oil phase $\left(\varphi_{O}=0.4243\right)$ and parent CDs $(13.93 \% \mathrm{w} / \mathrm{w})$ as stabilisers, the release of econazole nitrate and its antimicrobial effect is highly dependent on the type of $\mathrm{CD}$ used. It seems that $\gamma \mathrm{CD}$ impairs drug release from the resulting Pickering emulsions, regardless of the oil type. As such, the biocidal activity of such formulations against Candida albicans and Streptococcus aureus is absent. This effect is also $\mathrm{pH}$ dependent. On the contrary, emulsions formulated with $\alpha \mathrm{CD}$ or $\beta C D$ were as effective oreven better than the commerciallyavailable econazole nitrate (Pevaryl ${ }^{\circledR}$ cream), stabilised with surfactants. The plain Pickering emulsion bases, without the loaded drug, showed no antimicrobial activity [26]. Pickering emulsion stabilised with $\alpha \mathrm{CD} / \mathrm{PEG} 20,000$ hydrogel, loaded with econazole nitrate or miconazole nitrate, showed comparable efficiency against C. albicans as commercially available formulations of the same drug (Pevaryl ${ }^{\circledR}$ and Micatin ${ }^{\circledR}$ creams, respectively) [77]. With the use of phytochemicals like carvacrol and terpinene-4-ol as the oil phase of the Pickering emulsion $\left(\varphi_{\mathrm{O}}=0.44\right)$, the antimicrobial activity of the loaded drug may be further enhanced [73]. Very stable emulsions without petro-sourced surfactants or modified silica nanoparticles were obtained with carvacrol and $\beta \mathrm{CD}$ (45 and 10\% w/w, respectively). Such a relatively simple formulation was shown to be 2-fold more effective on $C$. albicans and methicillin-resistant Staphylococcus aureus (MRSA) than the commercial cream (Monistat Derm ${ }^{\circledR}$ ) containing the same dose of miconazole nitrate $(1 \% \mathrm{w} / \mathrm{w})$. Furthermore, it showed high activity against Escherichia coli, whereas the commercial formulation was completely inactive. The CD-stabilised Pickering emulsion was found to provide a synergistic effect against $C$. albicans and has the potential to disrupt preformed methicillin-resistant Streptococcus aureus (MRSA) biofilms [73].

A recent report from the same group evaluated the addition of undecylenic acid $(10 \% \mathrm{w} / \mathrm{w})$ to $\beta C D$ stabilized Pickering emulsions containing the same phytoantimicrobial oils [76]. These very stable emulsions showed acceptable $\mathrm{pH}$ and viscosity properties for topical skin applications. The carvacrol/undecylenic acid emulsion containing $1 \%(\mathrm{w} / \mathrm{w})$ of miconazoctylium bromide appeared to be the most antimicrobial active formulation. In addition to notable activity against $E$. coli, a potent anti-staphylococcal activity was observed against MRSA, with up to $390 \%$ greater inhibitory potency compared to commercially available formulations containing azole antifungal drugs (Monistat Derm ${ }^{\mathrm{TM}}$ Cream). Furthermore, this Pickering emulsion caused the eradication of MRSA biofilms. Such outstanding activities are attributed to the synergistic action of undecylenic acid (acting as an enzyme inhibitor) and carvacrol (acting as a membrane fluidizer) with the drug. Against $C$. albicans, this Pickering emulsion also showed comparable activity to commonly prescribed drugs. Nowadays, the pharmaceutical industry is focused on the development of more environmentally friendly pharmaceuticals that incorporate more sustainable processes and drugs. From this perspective, this highly efficient, surfactant-free, silica-free, and fully organic O/W Pickering emulsion can be considered a good example of how product candidates can be realized within a biobased economy and transition away from conventional development pathways [76]. Further development of such CD-based Pickering emulsions for clinical applications is currently underway as well.

Besides developing them for topical drug administration to the skin, CD-stabilised Pickering emulsions may be considered as dosage forms with the potential for transdermal drug delivery. Taguchi et al. demonstrated that the flux of captopril through hairless mouse skin from Pickering emulsions developed using $20 \%(\mathrm{w} / \mathrm{w})$ of $\beta \mathrm{CD}, 37 \%(\mathrm{w} / \mathrm{w})$ of isopropyl myristate, and $43 \%(\mathrm{w} / \mathrm{w})$ of water was approximately 6-times higher than that of the same emulsion stabilised with $20 \%(\mathrm{w} / \mathrm{w})$ of the surfactant, polyoxyethylene (60) hydrogenated castor oil [54]. Both formulations contained $5 \%(\mathrm{w} / \mathrm{w})$ captopril. Isopropyl myristate by itself is a wellknown permeation enhancer, but this study demonstrated that emulsified isopropyl myristate alone is not sufficient to obtain maximum enhancement of captopril skin permeation, which occurs only when $\beta C D$ is present in the system and indicates a degree of synergistic action between isopropyl myristate and $\beta C D$ to facilitate transdermal delivery of captopril.

Badr-Eldin et al. employed CD-stabilised Pickering emulsions as a base to formulate oral tablets of tadalafil, which is a poorly soluble drug used for erectile dysfunction management [74]. In the first phase, the authors optimised the formulation of CD-based Pickering emulsions using full factorial design. An emulsion containing $20 \mathrm{~mL}$ of sweet almond oil, $6 \mathrm{~g}$ of $\alpha \mathrm{CD}$, and $75 \mathrm{~mL}$ of water, had an emulsified droplet size of $0.45 \mu \mathrm{m}$ and was determined to be the most stable, while providing the highest drug solubility of $18.94 \pm 0.55 \mathrm{mg} / \mathrm{mL}$. However, the drug was loaded at a lower concentration of $15 \mathrm{mg} / \mathrm{mL}$, to avoid drug precipitation during processing. In the second phase, gelatine and spray-dried mannitol were added to the aqueous phase of the emulsion in different weight ratios, ranging from 6:0 to 0:6. The emulsions were loaded into $13 \mathrm{~mm}$ blister packs and subjected to lyophilization, which resulted in tablets with friability and hardness ranging from 0.23 to $0.71 \%$ and $3.30-6.27 \mathrm{~kg}$, respectively. The disintegration time of the tablets was rapid, ranging from 21 up to $158 \mathrm{~s}$. This approach resulted in a significant improvement in the in vitro release of tadalafil in $0.1 \mathrm{M} \mathrm{HCl}$. In such conditions, the drug alone did not dissolve, while the drug release from the tablets was dependent on the gelatine to mannitol ratio. 
Tablets containing a higher ratio of mannitol (3:3, 2:4 and $1: 5$, respectively) showed faster drug release, which was completed within 15 to $20 \mathrm{~min}$ in the dissolution test. Tablets were stable during 6 months of storage at ambient temperature and $60 \%$ relative humidity. After reconstitution in water, the tablets formed $\mathrm{O} / \mathrm{W}$ emulsions with droplet sizes comparable to those before storage. Such a formulation has the potential to efficiently enhance the oral bioavailability of poorly soluble drugs, like that already demonstrated for self (micro)emulsifying drug delivery systems, without the risks of irritations connected with the use of conventional surfactants [74].

In addition to delivering active pharmaceutical ingredients, Pickering emulsions stabilised with CDs may be a suitable platform for the development of different nutraceutical formulations. For example, high internal-phase Pickering emulsion stabilised with $\beta C D$ have been reported to be an effective delivery platform to protect lutein, a dietary supplement capable of reducing the progression of age-related macular degeneration, against UV-mediated degradation [9]. The observed protective capacity was related to the properties of the layer formed by insoluble complexes of $\beta C D$ and sunflower oil triglycerides at the $\mathrm{O} / \mathrm{W}$ interface that caused light scattering. Moreover, $\mathrm{CDs}$ can form multiple $\mathrm{W}_{1} / \mathrm{O} / \mathrm{W}_{2}$ emulsions suitable for encapsulation of living cells, like probiotic bacteria. For example, Lactobacillus delbruckii was entrapped in the inner aqueous phase of a $\mathrm{W}_{1} / \mathrm{O} / \mathrm{W}_{2}$ Pickering emulsion stabilised with $\beta C D$ [78]. Multiple emulsions consisted of $60 \% \mathrm{~W}_{1} / \mathrm{O}$ emulsion that contained $30 \%(\mathrm{~V} / \mathrm{V})$ of the aqueous bacterial culture $\left(10^{8} \mathrm{CFU} / \mathrm{mL}\right)$ and $60 \%$ $(\mathrm{V} / \mathrm{V})$ of canola oil emulsified with the aid of $10 \%(\mathrm{~V} / \mathrm{V})$ Span 80 . Such emulsions were then emulsified in $40 \%$ (V/V) of an external aqueous phase $\left(\mathrm{W}_{2}\right)$ containing 2.5 or $5 \%$ $(w / V) \beta C D$. The stability of multiple emulsions stabilised with $\beta C D$ was superior to those formulated with Tween 80 ( 1 or $2 \%, \mathrm{~V} / \mathrm{V}$ ) as an emulsifier in the outer aqueous phase. Moreover, the viability of bacteria in the $\beta \mathrm{CD}$-stabilised multiple emulsions was unaffected by the formulation components, while in those containing Tween 20 , the viability decreased as functions of time and emulsifier concentration. Micron-sized multiple Pickering emulsions entrapping Lactobacillus case $i$ were also prepared using $\beta C D$ as the emulsifier in the outer aqueous phase [79]. The primary emulsion contained $45 \%$ (V/V) sterile water containing bacterial culture, $45 \%(\mathrm{~V} / \mathrm{V})$ corn oil, and $10 \%(\mathrm{~V} / \mathrm{V})$ Span 80 and was dispersed in an outer aqueous phase containing $2.5 \%(\mathrm{w} / \mathrm{V})$ $\beta C D$, at different $\mathrm{W}_{1} / \mathrm{O}$ to $\mathrm{W}_{2}$ phase ratios. The formulation prepared at a 60:40 ratio provided effective protection of the entrapped $L$. case $i$ against bile salts, acid environments, and elevated temperature. These findings suggest that edible CD-based multiple Pickering emulsions have great potential as a platform to support more efficient delivery of probiotic bacteria to the gut.

\section{Concluding remarks and outlook}

While CD-based emulsions have already demonstrated excellent possibilities for healthcare and biotechnology applications such as topical drug delivery and cellular encapsulation, there is excellent potential to continue developing CD-based emulsions for new translational medicine applications, especially related to infectious disease treatment. The colloidal tectonics architecture of such systems provides the possibility to design an infinite number of new, smart, andflexible formulations having high environmental compatibility. As discussed herein, CDs can interact with a variety of lipids and one promising direction involves developing CD-based emulsions that incorporate medium-chain fatty acids and monoglycerides ( $\mathrm{C}_{6}$ to $\mathrm{C}_{12}$ chain length), which are among the most biologically potent lipids found in nature and exhibit antiinfective activity against membrane-enveloped viruses and bacteria through membrane-disruptive properties [93-96]. While antimicrobial lipids are highly active as components within supramolecular structures [e.g. in micelles that naturally form above the critical micelle concentration (CMC)], they tend to lose membrane-disruptive properties upon dilution in physiological environments due to micellar disaggregation and are typically inactive in monomeric form [97] below their corresponding CMC (see, e.g. biophysical and antiviral data in Refs. [98] and [99], respectively). To address this issue as well as to improve lipid solubility, a variety of liposomal, emulsion, and solid lipid nanoparticle strategies have been devised to encapsulate antimicrobial lipids with varying degrees of success for food and medical applications, including topical, oral, and parenteral administration uses [100]. Notably, the existing emulsion formulations have been limited to using conventional surfactants (e.g. Tween 20) and there is outstanding potential to explore developing CD-based emulsions to (1) create new types of supramolecular assemblies involving antimicrobial lipids (see, e.g. complexes of medium-chain fatty acids and peptide amphiphiles [101]with tuneable nanoscale morphologies and functionalities); (2) achieve controlled release of antimicrobial lipids; and (3) enable dilution-stable formulations to facilitate the membranedisruptive activities of antimicrobial lipids in physiological environments upon therapeutic administration. Since certain medium-chain fatty acids and monoglycerides also exhibit immune-modulating activities [102], there are also additional healthcare application possibilities, especially in conjunction with tableting for oral administration associated with nutraceutical and preventative health uses.

Moreover, CDs alone may act as virucidal agents due to their interaction with viral membrane lipids [103]. Lipid rafts, enriched in sphingolipids, cholesterol, and 
associated proteins, are special plasma membrane microdomains involved in several processes in viral infections. Cholesterol-rich microdomains appear to be a general feature of the entry mechanism of medically important viruses, including several coronaviruses, and hence are an attractive target. For example, DIMEB is highly efficient in depleting cholesterol from biomembranes, owing to its prominent affinity for inclusion complexation with cholesterol $[32,104]$. The extraction of cholesterol leads to the disorganization of lipid microdomains and the dissociation of proteins bound to lipid rafts. By that, DIMEB can potentially block downstream key molecules, such as receptors, involved in virus infectivity, thereby reducing the levels of proinflammatory molecules and/or affecting the autophagic process involved in both viral replication and clearance [105]. Furthermore, the combination of CDs with common disinfectants, like didecyldimethylammonium chloride and dodecyloctaglycol, presented synergistic effects against enveloped viruses (respiratory syncytial virus, herpes simplex virus type 1 , vaccinia virus) and fungi (C. albicans), as well as additive responses against bacteria ( $P$. aeruginosa) [103]. In this light, combining $\mathrm{CDs}$ and antimicrobial lipids into one formulation may boost antiviral effects of lipids against enveloped viruses, providing a novel approach to combat the coronavirus disease 2019 (COVID-19) pandemic [106]. Such possibilities are just one opportunity out of many that can emerge from future research efforts aimed at developing CD-based emulsions that incorporate bioactive lipids and other molecular components while highlighting how CDs - which are typically regarded as having low surface activity - are not only useful in terms of host-guest chemistry but also possess advantageous properties for interfacial science applications.

Author contributions MJand JAJ developed the idea for the article, MJ and BKY performed the literaturesearch and data analysis, MJ drafted the manuscript and prepared illustrationswhile JAJ critically revised the work. All authors read and approved the final versionof the manuscript.

Funding This research was supported by the International Research \& Development Program of the National Research Foundation of Korea (NRF) funded by the Ministry of Science and ICT (2020K1A3A1A39112724).

Data availability Alldata generated or analysed during this study are included in this publishedarticle.

Code availability Notapplicable.

\section{Declarations}

Conflict of interest Theauthors have no conflicts of interest to declare that are relevant to thecontent of this article.

\section{References}

1. Albert, C., Beladjine, M., Tsapis, N., Fattal, E., Agnely, F., Huang, N.: Pickering emulsions: preparation processes, key parameters governing their properties and potential for pharmaceutical applications. J. Control Release 309, 302-332 (2019). https://doi.org/10.1016/j.jconrel.2019.07.003

2. Tai, Z., Huang, Y., Zhu, Q., Wu, W., Yi, T., Chen, Z., Lu, Y.: Utility of Pickering emulsions in improved oral drug delivery. Drug Discov Today. 25, 2038-2045 (2020). https://doi.org/10. 1016/j.drudis.2020.09.012

3. Lémery, E., Briançon, S., Chevalier, Y., Bordes, C., Oddos, T., Gohier, A., Bolzinger, M.A.: Skin toxicity of surfactants: structure/toxicity relationships. Colloids. Surf A. Physicochem. Eng. Asp. 469, 166-179 (2015). https://doi.org/10. 1016/j.colsurfa.2015.01.019

4. Seweryn, A.: Interactions between surfactants and the skin theory and practice. Adv. Colloid. Interface Sci. 256, 242-255 (2018). https://doi.org/10.1016/j.cis.2018.04.002

5. Söderberg, L., Engblom, J., Lanbeck, P., Wahlgren, M.: Do surface active parenteral formulations cause inflammation? Int. J. Pharm. 484, 246-251 (2015). https://doi.org/10.1016/j.ijpha rm.2015.02.045

6. Jardak, K., Drogui, P., Daghrir, R.: Surfactants in aquatic and terrestrial environment: occurrence, behavior, and treatment processes. Environ. Pollut. Res. 23, 3195-2316 (2016). https:// doi.org/10.1007/s11356-015-5803-X

7. Yang, Y., Fang, Z., Chen, X., Zhang, W., Xie, Y., Chen, Y., Liu, Z., Yuan, W.: An overview of Pickering emulsions: solidparticle materials, classification, morphology, and applications. Front. Pharmacol. 8, 1-20 (2017). https://doi.org/10. 3389/fphar.2017.00287

8. Harman, C.L.G., Patel, M.A., Guldin, S., Davies, G.L.: Recent developments in Pickering emulsions for biomedical applications. Curr. Opin. Colloid Interface Sci. 39, 173-189 (2019). https://doi.org/10.1016/j.cocis.2019.01.017

9. Liu, Z., Geng, S., Jiang, Z., Liu, B.: Fabrication and characterization of food-grade Pickering high internal emulsions stabilized with $\beta$-cyclodextrin. Lwt 134, 110134 (2020). https:// doi.org/10.1016/j.lwt.2020.110134

10. Marto, J., Ascenso, A., Simoes, S., Almeida, A.J., Ribeiro, H.M.: Pickering emulsions: challenges and opportunities in topical delivery. Expert. Opin. Drug. Deliv. 13, 1093-1107 (2016). https://doi.org/10.1080/17425247.2016.1182489

11. Choi, S.J., Lee, J.K., Jeong, J., Choy, J.H.: Toxicity evaluation of inorganic nanoparticles: considerations and challenges. Mol. Cell. Toxicol. 9, 205-210 (2013). https://doi.org/10.1007/ s13273-013-0026-z

12. Tan, E.L., Potroz, M.G., Ferracci, G., Wang, L., Jackman, J.A., Cho, N.J.: Hydrophobic to superhydrophilic tuning of multifunctional sporopollenin for microcapsule and bio-composite applications. Appl. Mater. Today. 18, 100525 (2020). https:// doi.org/10.1016/j.apmt.2019.100525

13. Tan, E.L., Potroz, M.G., Ferracci, G., Jackman, J.A., Jung, H., Wang, L., Cho, N.J.: Light-induced surface modification of natural plant microparticles: toward colloidal science and cellular adhesion applications. Adv. Funct. Mater. 28, 1707568 (2018). https://doi.org/10.1002/adfm.201707568

14. Salem, L.B., Bosquillon, C., Dailey, L.A., Delattre, L., Martin, G.P., Evrard, B., Forbes, B.: Sparing methylation of $\beta$-cyclodextrin mitigates cytotoxicity and permeability induction in respiratory epithelial cell layers in vitro. J. Control. Release. 136, 110-116 (2009). https://doi.org/10.1016/j. jconrel.2009.01.019 
15. Li, P., Song, J., Ni, X., Guo, Q., Wen, H., Zhou, Q., Shen, Y., Huang, Y., Qiu, P., Lin, S., Hu, H.: Comparison in toxicity and solubilizing capacity of hydroxypropyl- $\beta$-cyclodextrin with different degree of substitution. Int. J. Pharm. 513, 347-356 (2016). https://doi.org/10.1016/j.ijpharm.2016.09.036

16. Stella, V.J., He, Q.: Cyclodextrins. Toxicol. Pathol. 36, 30-42 (2008). https://doi.org/10.1177/0192623307310945

17. Jansook, P., Loftsson, T.: CDs as solubilizers: effects of excipients and competing drugs. Int. J. Pharm. 379, 32-40 (2009). https://doi.org/10.1016/j.ijpharm.2009.06.005

18. Jansook, P., Ogawa, N., Loftsson, T.: Cyclodextrins: structure, physicochemical properties and pharmaceutical applications. Int. J. Pharm. 535, 272-284 (2018). https://doi.org/10.1016/j. ijpharm.2017.11.018

19. Popielec, A., Loftsson, T.: Effects of cyclodextrins on the chemical stability of drugs. Int. J. Pharm. 531, 532-542 (2017). https://doi.org/10.1016/j.ijpharm.2017.06.009

20. Arima, H., Higashi, T., Motoyama, K.: Improvement of the bitter taste of drugs by complexation with cyclodextrins: applications, evaluations and mechanisms. Ther. Deliv. 3, 633-644 (2012). https://doi.org/10.4155/tde.12.28

21. Anadolu, R., Sen, T., Tarimci, N., Birol, A., Erdem, C.: Improved efficacy and tolerability of retinoic acid in acne vulgaris: a new topical formulation with cyclodextrin complex psi. J. Eur. Acad. Dermatol. Venereol. 18, 416-421 (2004). https:// doi.org/10.1111/j.1468-3083.2004.00929.x

22. Scavone, C., Bonagura, A.C., Fiorentino, S., Cimmaruta, D., Cenami, R., Torella, M., Fossati, T., Rossi, F.: Efficacy and safety profile of diclofenac/cyclodextrin and progesterone/ cyclodextrin formulations: a review of the literature data. Drugs R\&D. 16, 129-140 (2016). https://doi.org/10.1007/ s40268-016-0123-2

23. Adeoye, O., Cabral-Marques, H.: Cyclodextrin nanosystems in oral drug delivery: a mini review. Int. J. Pharm. 531, 521-531 (2017). https://doi.org/10.1016/j.ijpharm.2017.04.050

24. Arima, H., Motoyama, K., Higashi, T.: Potential use of cyclodextrins as drug carriers and active pharmaceutical ingredients. Chem. Pharm. Bull. 65, 341-348 (2017). https://doi.org/10.1248/ cpb.c16-00779

25. Cada, D.J., Levien, T.L., Baker, D.E.: Sugammadex. Hosp Pharm. 51, 585-596 (2016). https://doi.org/10.1310/hpj5107-585

26. Leclercq, L., Nardello-Rataj, V.: Pickering emulsions based on cyclodextrins: a smart solution for antifungal azole derivatives topical delivery. Eur. J. Pharm. Sci. 82, 126-137 (2016). https:// doi.org/10.1016/j.ejps.2015.11.017

27. Mathapa, B.G., Paunov, V.N.: Cyclodextrin stabilised emulsions and cyclodextrinosomes. Phys. Chem. Chem. Phys. 15, 1790317914 (2013). https://doi.org/10.1039/c3cp52116h

28. Mathapa, B.G., Paunov, V.N.: Self-assembly of cyclodextrinoil inclusion complexes at the oil-water interface: a route to surfactant-free emulsions. J. Mater. Chem. A 1, 10836-10846 (2013). https://doi.org/10.1039/c3ta12108a

29. Duchêne, D., Bochot, A., Yu, S.C., Pépin, C., Seiller, M.: Cyclodextrins and emulsions. Int. J. Pharm. 266, 85-90 (2003). https:// doi.org/10.1016/S0378-5173(03)00384-3

30. Loftsson, T.: Drug solubilization by complexation. Int. J. Pharm. 531, 276-280 (2017). https://doi.org/10.1016/j.ijpharm.2017.08. 087

31. Dhiman, P., Bhatia, M.: Pharmaceutical applications of cyclodextrins and their derivatives. J. Incl. Phenom. Macrocycl. Chem. 98, 171-186 (2020). https://doi.org/10.1007/s10847-020-01029-3

32. Szente, L., Fenyvesi, É.: Cyclodextrin-lipid complexes: cavity size matters. Struct. Chem. 28, 479-492 (2017). https://doi.org/ 10.1007/s11224-016-0884-9

33. Szente, L., Szejtli, J., Szemán, J., Kató, L.: Fatty acid-cyclodextrin complexes: properties and applications. J. Incl. Phenom.
Macrocyclic Chem 16, 339-354 (1993). https://doi.org/10.1007/ BF00708714

34. Denz, M., Haralampiev, I., Schiller, S., Szente, L., Herrmann, A., Huster, D., Müller, P.: Interaction of fluorescent phospholipids with cyclodextrins. Chem. Phys. Lipids. 194, 37-48 (2016). https://doi.org/10.1016/j.chemphyslip.2015.07.017

35. Saokham, P., Loftsson, T.: $\gamma$-Cyclodextrin. Int. J. Pharm. 516, 278-292 (2017). https://doi.org/10.1016/j.ijpharm.2016.10.062

36. Singh, J., Pronobesh, N., Ashok, C., Sharma, K., Ram, V.: Preparation of gamma cyclodextrin stabilized solid lipid nanoparticles (SLNS) using stearic acid- $\gamma$-cyclodextrin inclusion complex. J. Incl. Phenom. Macrocycl. Chem. 80, 359-368 (2014). https:// doi.org/10.1007/s 10847-014-0415-5

37. Hammoud, Z., Khreich, N., Auezova, L., Fourmentin, S., Elaissari, A., Greige-Gerges, H.: Cyclodextrin-membrane interaction in drug delivery and membrane structure maintenance. Int. J. Pharm. 564, 59-76 (2019). https://doi.org/10.1016/j.ijpharm. 2019.03.063

38. Hădărugă, N.G., Hădărugă, D.I., Păunescu, V., Tatu, C., Ordodi, V.L., Bandur, G., Lupea, A.X.: Thermal stability of the linoleic $\mathrm{acid} / \alpha-$ and $\beta$-cyclodextrin complexes. Food Chem. 99, 500-508 (2006). https://doi.org/10.1016/j.foodchem.2005.08.012

39. Hădăruga, D.I., Ünlüsayin, M., Gruia, A.T., Birău, C., Rusu, G., Hădăruga, N.G.: Thermal and oxidative stability of Atlantic salmon oil (Salmo salar L.) and complexation with $\beta$-cyclodextrin. Beilstein J. Org. Chem. 12, 179-191 (2016). https://doi.org/10.3762/bjoc.12.20

40. Vestland, T.L., Jacobsen, Ø., Sande, S.A., Myrset, A.H., Klaveness, J., Lee, M.C., Jiang, X., Brenna, J.T., Abbaspourrad, A., Hădăruga, D.I., Ünlüsayin, M., Gruia, A.T., Birău, C., Rusu, G., Hădăruga, N.G., Hădărugă, N.G., Hădărugă, D.I., Păunescu, V., Tatu, C., Ordodi, V.L., Bandur, G., Lupea, A.X.: Oleogel-structured composite for the stabilization of $\omega 3$ fatty acids in fish oil. Food Chem. 9, 179-191 (2016). https://doi.org/10.1016/j.foodc hem.2005.08.012

41. David, I., Orboi, M.D., Simandi, M.D., Chirilă, C.A., Megyesi, C.I., Rădulescu, L., Drăghia, L.P., Lukinich-Gruia, A.T., Muntean, C., Hădărugă, D.I., Hădărugă, N.G.: Fatty acid profile of Romanian's common bean (Phaseolus vulgaris L.) lipid fractions and their complexation ability by $\beta$-cyclodextrin. PLoS One. 14, 1-25 (2019). https://doi.org/10.1371/journal.pone. 0225474

42. Vestland, T.L., Jacobsen, Ø., Sande, S.A., Myrset, A.H., Klaveness, J.: Compactible powders of omega- 3 and $\beta$-cyclodextrin. Food Chem. 185, 151-158 (2015). https://doi.org/10.1016/j. foodchem.2015.03.132

43. Szente, L., Singhal, A., Domokos, A., Song, B.: Cyclodextrins: assessing the impact of cavity size, occupancy, and substitutions on cytotoxicity and cholesterol homeostasis. Molecules. 23, 1-15 (2018). https://doi.org/10.3390/molecules23051228

44. Kiss, T., Fenyvesi, F., Bácskay, I., Váradi, J., Fenyvesi, É., Iványi, R., Szente, L., Tósaki, Á., Vecsernyés, M.: Evaluation of the cytotoxicity of $\beta$-cyclodextrin derivatives: evidence for the role of cholesterol extraction. Eur. J. Pharm. Sci. 40, 376-380 (2010). https://doi.org/10.1016/j.ejps.2010.04.014

45. Fenyvesi, É., Szemán, J., Csabai, K., Malanga, M., Szente, L.: Methyl-beta-cyclodextrins: the role of number and types of substituents in solubilizing power. J. Pharm. Sci. 103, 1443-1452 (2014). https://doi.org/10.1002/jps.23917

46. Loftsson, T.: Cyclodextrins in parenteral formulations. J. Pharm. Sci. 110, 654-664 (2021). https://doi.org/10.1016/j. xphs.2020.10.026

47. Kurkov, S.V., Loftsson, T.: Cyclodextrins. Int. J. Pharm. 453, 167-180 (2013). https://doi.org/10.1016/j.ijpharm.2012.06.055

48. Singhal, A., Szente, L., Hildreth, J.E.K.K., Song, B.: Hydroxypropyl-beta and -gamma cyclodextrins rescue cholesterol 
accumulation in Niemann-Pick C1 mutant cell via lysosomeassociated membrane protein 1. Cell Death Dis. 9, 1-13 (2018). https://doi.org/10.1038/s41419-018-1056-1

49. Wheeler, S., Sillence, D.J.: Niemann-Pick type C disease: cellular pathology and pharmacotherapy. J. Neurochem. 153, 674-692 (2020). https://doi.org/10.1111/jnc.14895

50. Mahjoubin-Tehran, M., Kovanen, P.T., Xu, S., Jamialahmadi, T., Sahebkar, A.: Cyclodextrins: potential therapeutics against atherosclerosis. Pharmacol. Ther. 214, 107620 (2020). https:// doi.org/10.1016/j.pharmthera.2020.107620

51. Lone, S.A.: Possible mechanisms of cholesterol-loaded cyclodextrin action on sperm during cryopreservation. Anim. Reprod. Sci. 192, 1-5 (2018). https://doi.org/10.1016/j.anireprosci.2018. 03.009

52. Hashizaki, K., Kageyama, T., Inoue, M., Taguchi, H., Ueda, H., Saito, Y.: Study on preparation and formation mechanism of $\mathrm{n}$-alkanol/water emulsion using $\alpha$-cyclodextrin. Chem. Pharm. Bull. 55, 1620-1625 (2007). https://doi.org/10.1248/cpb.55.1620

53. Inoue, M., Hashizaki, K., Taguchi, H., Saito, Y.: Emulsifying ability of $\beta$-cyclodextrins for common oils. J. Dispers. Sci. Technol. 31, 1648-1651 (2010). https://doi.org/10.1080/0193269090 3297058

54. Taguchi, H., Tanaka, H., Hashizaki, K., Saito, Y., Fujii, M.: Application of Pickering emulsion with cyclodextrin as an emulsifier to a transdermal drug delivery vehicle. Biol. Pharm. Bull. 42, 116-122 (2019). https://doi.org/10.1248/bpb.b18-00711

55. Hu, J.-W.W., Yen, M.-W.W., Wang, A.-J.J., Chu, I.-M.M.: Effect of oil structure on cyclodextrin-based Pickering emulsions for bupivacaine topical application. Colloids. Surf B. Biointerfaces. 161, 51-58 (2018). https://doi.org/10.1016/j.colsurfb.2017.10. 001

56. Leclercq, L.: Get beyond limits: from colloidal tectonics concept to the engineering of eco-friendly catalytic systems. Front. Chem. 6, 168 (2018). https://doi.org/10.3389/fchem.2018.00168

57. Hashizaki, K., Kageyama, T., Inoue, M., Taguchi, H., Saito, Y.: Preparation and characterization of cycloalkanol/water emulsion using $\alpha$-cyclodextrin as an emulsifier. J. Dispersion Sci. Technol. 30, 852-856 (2009). https://doi.org/10.1080/019326908026440 38

58. Diaz-Salmeron, R., Chaab, I., Carn, F., Djabourov, M., Bouchemal, K.: Pickering emulsions with $\alpha$-cyclodextrin inclusions: Structure and thermal stability. J. Colloid. Interface. Sci. 482, 48-57 (2016). https://doi.org/10.1016/j.jcis.2016.07.033

59. Hamoudi, M.C., Bourasset, F., Domergue-Dupont, V., Gueutin, C., Nicolas, V., Fattal, E., Bochot, A.: Formulations based on alpha cyclodextrin and soybean oil: An approach to modulate the oral release of lipophilic drugs. J. Control. Release. 161, 861-867 (2012). https://doi.org/10.1016/j.jconrel.2012.05.032

60. Trichard, L., Fattal, E., le Bas, G., Duchêne, D., Grossiord, J.L., Bochot, A.: Formulation and characterisation of beads prepared from natural cyclodextrins and vegetable, mineral or synthetic oils. Int. J. Pharm. 354, 88-94 (2008). https://doi.org/10.1016/j. ijpharm.2007.10.029

61. Aburahma, M.H.: Insights on novel particulate self-assembled drug delivery beads based on partial inclusion complexes between triglycerides and cyclodextrins. Drug Deliv. 23, 22052219 (2016). https://doi.org/10.3109/10717544.2014.956240

62. Hamoudi, M.C., Bochot, A.: Oil-cyclodextrin based beads for oral delivery of poorly-soluble drugs. Curr. Top. Med. Chem. 14, 510-517 (2014). https://doi.org/10.2174/156802661366613 1219124539

63. Laza-Knoerr, A., Huang, N., Grossiord, J.L., Couvreur, P., Gref, R.: Interfacial rheology as a tool to study the potential of cyclodextrin polymers to stabilize oil-water interfaces. J. Incl. Phenom. Macrocycl. Chem. 69, 475-479 (2011). https://doi.org/10. 1007/s10847-010-9805-5
64. Kawano, S., Kida, T., Akashi, M., Sato, H., Shizuma, M., Ono, D.: Preparation of Pickering emulsions through interfacial adsorption by soft cyclodextrin nanogels. Beilstein J. Org. Chem. 11, 2355-2364 (2015). https://doi.org/10.3762/ bjoc. 11.257

65. Inoue, M., Hashizaki, K., Taguchi, H., Saito, Y.: Emulsion preparation using $\beta$-cyclodextrin and its derivatives acting as an emulsifier. Chem. Pharm. Bull. 56, 1335-1337 (2008). https://doi.org/ $10.1248 / \mathrm{cpb} .56 .1335$

66. Hu, Y., Qiu, C., Jin, Z., Qin, Y., Zhan, C., Xu, X., Wang, J.: Pickering emulsions with enhanced storage stabilities by using hybrid $\beta$-cyclodextrin/short linear glucan nanoparticles as stabilizers. Carbohydr. Polym. 229, 115418 (2020). https://doi.org/10.1016/j. carbpol.2019.115418

67. Luviano, A.S., Hernández-Pascacio, J., Ondo, D., Campbell, R.A., Piñeiro, Á, Campos-Terán, J., Costas, M.: Highly viscoelastic films at the water/air interface: $\alpha$-Cyclodextrin with anionic surfactants. J. Colloid Interface Sci. 565, 601-613 (2020). https:// doi.org/10.1016/j.jcis.2019.12.012

68. Xiao, Z., Liu, Y., Niu, Y., Kou, X.: Cyclodextrin supermolecules as excellent stabilizers for Pickering nanoemulsions. Colloids Surf. A Physicochem. Eng Asp. 588, 124367 (2020). https://doi. org/10.1016/j.colsurfa.2019.124367

69. Ringard-Lefebvre, C., Bochot, A., Memisolu, E., Charon, D., Duchene, D., Baszkin, A.: Effect of spread amphiphilic $\beta$-cyclodextrins on interfacial properties of the oil/water system. Colloids Surf. B Biointerfaces. 25, 109-117 (2002). https://doi. org/10.1016/S0927-7765(01)00297-1

70. Xi, Y., Luo, Z., Lu, X., Peng, X.: Modulation of cyclodextrin particle amphiphilic properties to stabilize Pickering emulsion. J. Agric. Food Chem. 66, 228-237 (2018). https://doi.org/10.1021/ acs.jafc. $7 b 03940$

71. Niu, H., Chen, W., Chen, W., Yun, Y., Zhong, Q., Fu, X., Chen, H., Liu, G.: Preparation and characterization of a modified- $\beta$ Cyclodextrin/ $\beta$-Carotene inclusion complex and its application in Pickering emulsions. J. Agric. Food Chem. 67, 12875-12884 (2019). https://doi.org/10.1021/acs.jafc.9b05467

72. Ke, D., Chen, W., Chen, W., Yun, Y.H., Zhong, Q., Su, X., Chen, H.: Preparation and characterization of octenyl succinate $\beta$-cyclodextrin and Vitamin E inclusion complex and its application in emulsion. Molecules 25, 654 (2020). https://doi.org/10. 3390/molecules 25030654

73. Leclercq, L., Tessier, J., Douyère, G., Nardello-Rataj, V., Schmitzer, A.R.: Phytochemical- and cyclodextrin-based Pickering Emulsions: natural potentiators of antibacterial, antifungal, and antibiofilm activity. Langmuir 36, 4317-4323 (2020). https:// doi.org/10.1021/acs.langmuir.0c00314

74. Badr-Eldin, S.M., Labib, G.S., Aburahma, M.H.: Eco-friendly tadalafil Surfactant-free dry emulsion tablets (SFDETs) stabilized by in situ self-assembled aggregates of natural oil and native cyclodextrins. AAPS Pharm. Sci. Tech. 20, 1-12 (2019). https://doi.org/10.1208/s12249-019-1450-8

75. Yu, S.C., Bochot, A., le Bas, G., Chéron, M., Mahuteau, J., Grossiord, J.L., Seiller, M., Duchêne, D.: Effect of camphor/cyclodextrin complexation on the stability of O/W/O multiple emulsions. Int. J. Pharm. 261, 1-8 (2003). https://doi.org/10.1016/S03785173(03)00261-8

76. Leclercq, L., Tessier, J., Nardello-Rataj, V., Schmitzer, A.R.: Highly active, entirely biobased antimicrobial Pickering emulsions. ChemMedChem. 16, 2223-2230 (2021). https://doi.org/ $10.1002 / \mathrm{cmdc} .202100030$

77. Leclercq, L., Dechézelles, J.F., Rauwel, G., Nardello-Rataj, V.: In vitro study of versatile drug formulations based on $\alpha$-cyclodextrin and polyethylene glycol using colloidal tectonics. J. Drug Deliv. Sci. Technol. 59, 101913 (2020). https://doi. org/10.1016/j.jddst.2020.101913 
78. Eslami, P., Davarpanah, L., Vahabzadeh, F.: Encapsulating role of $\beta$-cyclodextrin in formation of Pickering water-in-oil-in-water (W1/O/W2) double emulsions containing Lactobacillus dellbrueckii. Food Hydrocoll. 64, 133-148 (2017). https://doi.org/ 10.1016/j.foodhyd.2016.10.035

79. Eslami, P., Forootan, K., Davarpanh, L., Vahabzadeh, F.: Incorporation of lactobacillus casei into the inner phase of the water-in-oil-in-water (W1/O/W2) emulsion prepared with $\beta$-cyclodextrin and bacterial survival in a model gastric environment. Appl. Food Biotechnol. 7, 171-182 (2020). https://doi.org/ 10.22037/afb.v7i3.28877

80. Wu, J., Ma, G.H.: Recent studies of Pickering emulsions: particles make the difference. Small. 12, 4633-4648 (2016). https:// doi.org/10.1002/smll.201600877

81. Vladisavljević, G.T.: Preparation of microemulsions and nanoemulsions by membrane emulsification. Colloids Surf. A Physicochem. Eng Asp 579, 123709 (2019). https://doi.org/10.1016/j. colsurfa.2019.123709

82. Serge, L., Serpelloni, M., Piochurent, D.: A study of $\beta$-cyclodextrin-stabilized paraffin oil / water emulsions. J. Cosmet. Sci. 50, 15-22 (1999)

83. Davarpanah, L., Vahabzadeh, F.: Formation of oil-in-water $(\mathrm{O} / \mathrm{W})$ Pickering emulsions via complexation between $\beta$-cyclodextrin and selected organic solvents. Starch/Staerke. 64, 898-913 (2012). https://doi.org/10.1002/star.201200027

84. Saffarionpour, S.: Nanocellulose for stabilization of Pickering emulsions and delivery of nutraceuticals and its interfacial adsorption mechanism. Food. Bioproc Tech. 13, 1292-1328 (2020). https://doi.org/10.1007/s11947-020-02481-2

85. Xia, T., Xue, C., Wei, Z.: Physicochemical characteristics, applications and research trends of edible Pickering emulsions. Trends Food Sci. Technol. 107, 1-15 (2021). https://doi.org/10.1016/j. tifs. 2020.11 .019

86. Li, X., Li, H., Xiao, Q., Wang, L., Wang, M., Lu, X., York, P., Shi, S., Zhang, J.: Two-way effects of surfactants on Pickering emulsions stabilized by the self-assembled microcrystals of $\alpha$-cyclodextrin and oil. Phys. Chem. Chem. Phys. 16, 1405914069 (2014). https://doi.org/10.1039/c4cp00807c

87. Kibici, D., Kahveci, D.: Effect of emulsifier type, maltodextrin, and $\beta$-Cyclodextrin on physical and oxidative stability of oil-inwater emulsions. J. Food Sci. 84, 1273-1280 (2019). https://doi. org/10.1111/1750-3841.14619

88. Potier, J., Menuel, S., Chambrier, M.H., Burylo, L., Blach, J.F., Woisel, P., Monflier, E., Hapiot, F.: Pickering emulsions based on supramolecular hydrogels: application to higher olefins' hydroformylation. ACS Catal. 3, 1618-1621 (2013). https://doi.org/ $10.1021 / \operatorname{cs} 4002282$

89. Tayeb, H.H., Sainsbury, F.: Nanoemulsions in drug delivery: formulation to medical application. Nanomedicine. 13, 2507-2525 (2018). https://doi.org/10.2217/nnm-2018-0088

90. Wang, J., Cai, Z.: Investigation of inclusion complex of miconazole nitrate with $\beta$-cyclodextrin. Carbohydr. Polym. 72, 255-260 (2008). https://doi.org/10.1016/j.carbpol.2007.08.009

91. Rawat, A., Gupta, S.S., Kalluri, H., Lowenborg, M., Bhatia, K., Warner, K.: Rheological characterization in the development of topical drug products. In: Perrie, Y. (ed.) AAPS advances in the pharmaceutical sciences series, pp. 3-45. Springer, New York (2019)

92. Inoue, M., Hashizaki, K., Taguchi, H., Saito, Y.: Preparation and characterization of $n$-alkane/water emulsion stabilized by cyclodextrin. J. Oleo Sci. 58, 85-90 (2009). https://doi.org/10.5650/ jos. 58.85

93. Casillas-Vargas, G., Ocasio-Malavé, C., Medina, S., MoralesGuzmán, C., del Valle, R.G., Carballeira, N.M., Sanabria-Ríos, D.J.: Antibacterial fatty acids: An update of possible mechanisms of action and implications in the development of the next-generation of antibacterial agents. Prog Lipid. Res. 82, 101093 (2021)

94. Yoon, B.K., Jeon, W.Y., Sut, T.N., Cho, N.J., Jackman, J.A.: Stopping membrane-enveloped viruses with nanotechnology strategies: toward antiviral drug development and pandemic preparedness. ACS Nano. 15, 125-148 (2021). https://doi.org/ 10.1021/acsnano.0c07489

95. Thormar, H., Hilmarsson, H.: The role of microbicidal lipids in host defense against pathogens and their potential as therapeutic agents. Chem. Phys. Lipids 150, 1-11 (2007). https://doi.org/10. 1016/J.CHEMPHYSLIP.2007.06.220

96. Fischer, C.L.: Antimicrobial activity of host-derived lipids. Antibiotics 9, 75 (2020). https://doi.org/10.3390/ANTIBIOTICS9020 075

97. Yoon, B.K., Jackman, J.A., Valle-González, E.R., Cho, N.J.: Antibacterial free fatty acids and monoglycerides: Biological activities, experimental testing, and therapeutic applications. Int. J. Mol.Sci. 19, 1114 (2018). https://doi.org/10.3390/ijms1 9041114

98. Yoon, B.K., Jackman, J.A., Kim, M.C., Sut, T.N., Cho, N.J.: Correlating membrane morphological responses with micellar aggregation behavior of capric acid and monocaprin. Langmuir. 33, 2750-2759 (2017). https://doi.org/10.1021/acs.langmuir. $6 \mathrm{~b} 03944$

99. Jackman, J.A., Hakobyan, A., Zakaryan, H., Elrod, C.C.: Inhibition of African swine fever virus in liquid and feed by medium-chain fatty acids and glycerol monolaurate. J. Anim. Sci. Biotechnol. 11, 1-10 (2020). https://doi.org/10.1186/ s40104-020-00517-3

100. Jackman, J.A., Yoon, B.K., Li, D., Cho, N.J.: Nanotechnology formulations for antibacterial free fatty acids and monoglycerides. Molecules. 21, 305 (2016). https://doi.org/10.3390/molec ules21030305

101. Yu, Z., Erbas, A., Tantakitti, F., Palmer, L.C., Jackman, J.A., de La Cruz, M.O., Cho, N.J., Stupp, S.I.: Co-assembly of peptide amphiphiles and lipids into supramolecular nanostructures driven by anioni $-\pi$ Interactions. J. Am. Chem. Soc. 139, 7823-7830 (2017). https://doi.org/10.1021/jacs.7b02058

102. Zhang, M.S., Tran, P.M., Wolff, A.J., Tremblay, M.M., Fosdick, M.G., Houtman, J.C.D.: Glycerol monolaurate induces filopodia formation by disrupting the association between LAT and SLP76 microclusters. Sci. Signal 11, 9095 (2018). https://doi.org/10. 1126/scisignal.aam 9095

103. Leclercq, L., Nardello-Rataj, V.: How to improve the chemical disinfection of contaminated surfaces by viruses, bacteria and fungus? Eur. J. Pharm. Sci. 155, 10559 (2020). https://doi.org/ 10.1016/j.ejps.2020.105559

104. Mandal, P., Noutsi, P., Chaieb, S.: Cholesterol depletion from a ceramide/cholesterol mixed monolayer: a Brewster angle microscope study. Sci. Rep. 6, 26907 (2016). https://doi.org/10.1038/ srep26907

105. Sorice, M., Misasi, R., Riitano, G., Manganelli, V., Martellucci, S., Longo, A., Garofalo, T., Mattei, V.: Targeting lipid rafts as a strategy against Coronavirus. Front. Cell Dev. Biol. 8, 1848 (2021). https://doi.org/10.3389/fcell.2020.618296

106. Carrouel, F., Conte, M.P., Fisher, J., Gonçalves, L.S., Dussart, C., Llodra, J.C., Bourgeois, D.: COVID-19: A recommendation to examine the effect of Mouthrinses with $\beta$-Cyclodextrin combined with Citrox in preventing infection and progression. J. Clin. Med. 9, 1126 (2020). https://doi.org/10.3390/jcm9041126

Publisher's Note Springer Nature remains neutral with regard to jurisdictional claims in published maps and institutional affiliations. 